\title{
Constraints on the loss of matrix-sited helium during vacuum crushing of mafic phenocrysts
}

\author{
P.-H. Blard ${ }^{\mathrm{a}, *}$, N. Puchol ${ }^{\text {b }}$, K.A. Farley ${ }^{\mathrm{a}}$ \\ a Division of Geological and Planetary Sciences, MC 100-23, California Institute of Technology, Pasadena, CA 91125, USA \\ ${ }^{\mathrm{b}}$ Ecole Normale Supérieure de Lyon, 69364 Lyon, France
}

Received 21 December 2007; accepted in revised form 24 May 2008; available online 5 June 2008

\begin{abstract}
Vacuum crushing is an efficient technique to selectively release the mantle-derived helium component trapped within olivine and pyroxene phenocrysts. However, contrary to previous assumptions, recent studies have shown that this method may liberate significant matrix-sited cosmogenic ${ }^{3} \mathrm{He}\left({ }^{3} \mathrm{He}_{\mathrm{c}}\right)$ or radiogenic ${ }^{4} \mathrm{He}\left({ }^{4} \mathrm{He}^{*}\right)$. Because this loss may bias both the determination of magmatic ${ }^{3} \mathrm{He} /{ }^{4} \mathrm{He}$ ratios and the accuracy of ${ }^{3} \mathrm{He}_{\mathrm{c}}$ measurements, it is essential to understand what mechanism is responsible and under what conditions matrix helium loss is manifest. To address this question, olivines and pyroxenes with various amounts of matrix-sited ${ }^{3} \mathrm{He}$ (from $10^{7}$ to $10^{11}$ at. $\mathrm{g}^{-1}$ ) were crushed in air or in vacuum using several crushing devices. Sample temperature was controlled during each crushing experiment, and ranged from 25 to $325^{\circ} \mathrm{C}$. The resulting powders were then sieved to obtain several homogeneous grain fractions ranging between $<10$ and $>300 \mu \mathrm{m}$. The ${ }^{3} \mathrm{He}_{\mathrm{c}}$ concentrations measured in each fraction clearly show that significant ${ }^{3} \mathrm{He}_{\mathrm{c}}$ loss $(>20 \%)$ affects only the finest fraction $(<10 \mu \mathrm{m})$ and, importantly, only under hot conditions (here $\left.T \geqslant 300{ }^{\circ} \mathrm{C}\right)$. Even the smallest fractions $(<10 \mu \mathrm{m})$ quantitatively retain matrix-sited ${ }^{3} \mathrm{He}_{\mathrm{c}}$ when crushed under cold conditions $\left(T \leqslant 25{ }^{\circ} \mathrm{C}\right)$, regardless of the duration and energy of crushing. These results invalidate the model previously proposed by (Yokochi R., Marty B., Pik R. and Burnard P. (2005) High ${ }^{3} \mathrm{He} /{ }^{4} \mathrm{He}$ ratios in peridotite xenoliths from SW Japan revisited: evidence for cosmogenic ${ }^{3} \mathrm{He}$ released by vacuum crushing. Geochem. Geophys. Geosyst. 6, doi:10.1029/2004GC000836) that involved spallation tracks and implied that the magnitude of loss was mainly controlled by the grain size. Moreover, new diffusion experiments were carried out to constrain the diffusivity of matrix-sited helium in crushed olivines. When used to model diffusive ${ }^{3} \mathrm{He}_{\mathrm{c}}$ loss as a function of grain size during crushing, these new data predict the observed release fairly well. Therefore, we conclude that temperature-enhanced volume diffusion is one of the main mechanisms controlling the release of ${ }^{3} \mathrm{He}_{\mathrm{c}}$ during crushing. For future applications, special attention should thus be paid to control the grain size, the crushing duration, and the temperature of the sample.
\end{abstract}

(c) 2008 Elsevier Ltd. All rights reserved.

\section{INTRODUCTION}

Helium isotopes trapped in inclusions in mafic phenocrysts are a very useful geochemical proxy for characterizing mantle sources (e.g., Kurz et al., 1982; Stuart et al., 2003). In addition, cosmogenic ${ }^{3} \mathrm{He}$ in the matrix of mafic phases (Kurz, 1986a) is a useful tool for understanding Earth-surface processes, not only because its nuclear stability permits

\footnotetext{
${ }^{*}$ Corresponding author.

E-mail address: blard@gps.caltech.edu (P.-H. Blard).
}

quantitative constraints over several million years of exposure (Blard et al., 2006a), but also because its low detection limit compared to its high production rate allow quantification of young exposure events $(<10 \mathrm{ka})$ (e.g., Kurz et al., 1990). However, accurate determination of magmatic helium isotopic ratios and cosmogenic ${ }^{3} \mathrm{He}\left({ }^{3} \mathrm{He}_{\mathrm{c}}\right)$ abundances require very specific analytical conditions to isolate each of these helium components. In the case of olivines and pyroxenes, which are the most common minerals used for such applications, vacuum crushing has been widely adopted because of its supposed ability to selectively release the magmatic helium contained within fluid and melt inclusions, 
without extracting matrix-sited helium (Kurz, 1986b). However, recent studies have demonstrated that this assumption is not always valid and that prolonged crushing may cause the extraction of a significant amount of matrix-sited helium (Scarsi, 2000). The demonstration that such loss can occur has led (Yokochi et al., 2005) and (Moreira and Madureira, 2005) to revisit several determinations of magmatic helium isotopic ratios. It also caused (Blard et al., 2006b) to question the accuracy of certain cosmogenic ${ }^{3} \mathrm{He}$ measurements.

Correction for magmatic ${ }^{3} \mathrm{He}$ is usually performed according to the equation (Kurz, 1986a):

${ }^{3} \mathrm{He}_{\mathrm{c}}={ }^{3} \mathrm{He}_{\text {fusion }}-\left({ }^{3} \mathrm{He} /{ }^{4} \mathrm{He}\right)_{\text {crush }} \times{ }^{4} \mathrm{He}_{\text {fusion }}$

where ${ }^{3} \mathrm{He}_{\text {fusion }}$ and ${ }^{4} \mathrm{He}_{\text {fusion }}$ are the concentrations measured by vacuum fusion of the phenocrysts and $\left({ }^{3} \mathrm{He} /\right.$ $\left.{ }^{4} \mathrm{He}\right)_{\text {crush }}$ is the helium isotopic ratio determined by vacuum crushing. Consequently, extraction of a significant amount of cosmogenic ${ }^{3} \mathrm{He}$ during the crushing step may induce overestimation of the fluid inclusion ${ }^{3} \mathrm{He} /{ }^{4} \mathrm{He}$ ratio. If ignored, this partial ${ }^{3} \mathrm{He}_{\mathrm{c}}$ release may also lead to underestimation of the actual ${ }^{3} \mathrm{He}_{\mathrm{c}}$ concentration, as a result of the combined effects of (i) inaccurately high measured crushing ${ }^{3} \mathrm{He} /{ }^{4} \mathrm{He}$ ratios and (ii) unquantified loss of the isotope of interest $\left({ }^{3} \mathrm{He}_{\mathrm{c}}\right)$. Moreover, the mechanisms controlling the release of matrix-sited ${ }^{3} \mathrm{He}_{\mathrm{c}}$ are not yet understood and this uncertainty hampers the development of alternative strategies to avoid matrix helium loss during crushing. Several recent studies (Moreira and Madureira, 2005; Yokochi et al., 2005; Blard et al., 2006b) proposed that the crushing release of ${ }^{3} \mathrm{He}_{\mathrm{c}}$ was controlled either by (i) a mechanism involving spallation tracks, that may provide an efficient pathway for helium extraction when tracks encounter newly created fractures or (ii) helium release at the fractured surface due to lattice distortion caused by plastic deformation of the grain during crushing. Both proposed mechanisms are strongly dependent on granulometry and are supposed to be efficient even at low temperature. Moreira and Madureira (2005) and Yokochi et al. (2005) ruled out the possibility that volume diffusion was the main mechanism responsible of crushing loss, basing their conclusions on the observed range of temperatures reached during crushing ( $T$ $<100{ }^{\circ} \mathrm{C}$ ) and the diffusion data of (Trull et al., 1991). However these hypotheses still need definitive testing.

In this study, we present results from new experiments designed to address these issues and to establish the mechanisms controlling release of matrix-sited helium during vacuum crushing. We carried out several crushing experiments, both in vacuum and in air, using different crushing devices. In particular, the temperature of the samples was controlled during crushing. After crushing, ${ }^{3} \mathrm{He}_{\mathrm{c}}$ was determined on samples that were split into several size fractions from $<10$ to $>300 \mu \mathrm{m}$. These experiments reveal that significant loss $(>20 \%)$ only affects the finest fraction $(<10 \mu \mathrm{m})$ and, importantly, only under hot conditions during crushing (here the experiment was performed at $\geqslant 300{ }^{\circ} \mathrm{C}$ ). The present study also provides new helium diffusivity data using proton-irradiated olivines (Shuster et al., 2004). As discussed in Section 4, these results provide support that temperature-dependent diffusion may control the release of matrix-sited ${ }^{3} \mathrm{He}_{\mathrm{c}}$ during vacuum crushing.

\section{METHODS}

\subsection{Sample description}

\subsubsection{Geological samples with natural spallation-induced ${ }^{3} \mathrm{He}_{\mathrm{c}}$}

The studied mafic phenocrysts come from two different moraine boulders exposed to cosmic rays since the Late Pleistocene glacial retreat, but with distinct geological settings and exposure histories.

Sample MK9 is a cobble of $20 \mathrm{~cm}$ diameter that was collected on a $\sim 15$-ka-old recessional moraine deposited at $3570 \mathrm{~m}$ on the southern slope of Mauna Kea volcano (Hawaii, $19^{\circ} \mathrm{N}$ ) (Blard et al., 2007). This cobble is an alkali basalt that is very rich $(>10 \%)$ in coarse olivine $\left(\mathrm{Fo}_{83}\right)$ and clinopyroxene (diopside) phenocrysts (average diameter $\sim 5 \mathrm{~mm}$ ). Both minerals have fluid and melt inclusions ranging in size between 5 and $40 \mu \mathrm{m}$. Given that the eruption age of this basalt is $\sim 100 \mathrm{ka}$ and its $\mathrm{U}$ and Th contents are, respectively, lower than 0.3 and $0.8 \mathrm{ppm}$ (Wolfe et al., 1997), the concentration of the ingrown radiogenic ${ }^{4} \mathrm{He}$ is very low within the phenocrysts $\left(<3 \times 10^{9}\right.$ at. $\left.\mathrm{g}^{-1}\right)$. A previous measurement (Blard et al., 2007) established that the cosmogenic ${ }^{3} \mathrm{He}$ content of MK9D phenocrysts is $8.7 \pm 0.3$ and $8.5 \pm 0.3 \times 10^{6}$ at. $\mathrm{g}^{-1}$ for olivines and pyroxenes, respectively. Therefore, even if radiogenic ${ }^{4} \mathrm{He}$ was neglected, this would not bias the corrected ${ }^{3} \mathrm{He}_{\mathrm{c}}$ by more than $0.5 \%$. The helium in these phenocrysts can thus be considered as a two component system: ${ }^{3} \mathrm{He}$ is only cosmogenic and magmatic and ${ }^{4} \mathrm{He}$ is only magmatic, and the use of Eq. (1) is therefore appropriate. Moreover, because magmatic ${ }^{4} \mathrm{He}$ is quite low in these phenocrysts $\left(<3 \times 10^{10}\right.$ at. $\left.\mathrm{g}^{-1}\right)$, correction for magmatic ${ }^{3} \mathrm{He}$ is not more than $5 \%$ of the total ${ }^{3} \mathrm{He}_{\mathrm{c}}$ and does not represent a significant source of uncertainty in the published experiment (Blard et al., 2007). Consequently, the total uncertainty associated with the ${ }^{3} \mathrm{He}_{\mathrm{c}}$ determination should be approximately the total reproducibility of the analytical system, i.e. few \% (Farley et al., 2006). This point is important given that the experiments described in the following section aim to detect variations in ${ }^{3} \mathrm{He}$ concentrations of as little as $10 \%$. Because several grams of pure MK9D olivines and clinopyroxenes are available, this sample is ideal for the multiple crushing experiments carried out here on separate mineral phases.

Sample TU8 was collected on the flat surface at the top of a boulder ( $\sim 2 \mathrm{~m}$ in height) located at $3750 \mathrm{~m}$ on an 18 - to 15-ka terminal fluvio-glacial moraine (Blard et al., 2008), on the southern flank of Cerro Tunupa, which borders the Salar de Uyuni (Bolivian Altiplano, 20 ${ }^{\circ} \mathrm{S}$ ). This rock is an andesite bearing $<1 \mathrm{~mm}$ phenocrysts of clinopyroxene (diopside composition: (Ca0.83, $\mathrm{Na} 0.04)(\mathrm{Mg} 0.82, \mathrm{Fe} 0.29$, $\left.\mathrm{Al0.06})\left(\mathrm{SiO}_{3}\right)_{2}\right)$. These phenocrysts have melt inclusions of $10-40 \mu \mathrm{m}$ diameter, but they appear to be almost free of fluid inclusions. Although the eruption age of this andesite is not precisely known, the emplacement of the Tunupa volcano is younger than $5 \mathrm{Ma}$ (Villeneuve et al., 2002). Thus, over this time period, given the Li concentration measured in these diopsides ( $<60 \mathrm{ppm}$, Blard et al., 2008), nucleogenic ${ }^{3} \mathrm{He}\left({ }^{3} \mathrm{He}_{\mathrm{n}}\right)$ (Andrews and Kay, 1982; Andrews, 1985) is less 
than $5 \%$ of the ${ }^{3} \mathrm{He}_{\mathrm{c}}$ concentration of $1.88 \pm 0.04 \times$ $10^{7}$ at. $\mathrm{g}^{-1}$ that has been measured in the TU8 pyroxenes (Blard et al., 2008). This estimate takes into account the proportion of ${ }^{3} \mathrm{He}_{\mathrm{n}}$ that is produced in the andesite matrix and implanted in these $\sim 300 \mu \mathrm{m}$ grains (Farley et al., 2006). Given the helium closure age of these minerals $(\leqslant 5 \mathrm{Ma})$, as well as the $\mathrm{U}$ and $\mathrm{Th}$ concentration in these andesites ( $\mathrm{U}$ $\leqslant 2$ ppm and Th $\leqslant 10$ ppm, Blard et al., 2008) and the diposide-lava partition coefficient of U-Th (from 0.11 to 0.15 , Blard et al., 2008), most of the ${ }^{4} \mathrm{He}$ extracted by fusing TU8 clinopyroxenes $\left(5 \pm 0.5 \times 10^{12}\right.$ at. $\left.^{-1}\right)$ results from radiogenic ingrowth. Preliminary results of vacuum crushing (Blard et al., 2008) also revealed that the total magmatic ${ }^{4} \mathrm{He}$ concentration is about $6 \times 10^{10}$ at. $\mathrm{g}^{-1}$. If we make the reasonable assumption that the uncertainty of this measured magmatic ${ }^{4} \mathrm{He}$ concentration is $100 \%$ and that the trapped ${ }^{3} \mathrm{He} /{ }^{4} \mathrm{He}$ ratio is $8 \mathrm{Ra}$, then the magmatic ${ }^{3} \mathrm{He}$ correction $\left(6.7 \pm 6.7 \times 10^{5}\right.$ at. $\left.\mathrm{g}^{-1}\right)$ does not represent more than $1 \%$ of the total ${ }^{3} \mathrm{He}_{\mathrm{c}}$ concentration $(1.84 \pm 0.04 \times$ $10^{7}$ at. $\mathrm{g}^{-1}$ ). This consideration is important in the case of TU8 pyroxenes, because it implies that, despite this three component mixture, the magmatic ${ }^{3} \mathrm{He}$ correction does not represent a significant source of uncertainty. Moreover, preliminary results (Blard et al., 2008) obtained by fusing several aliquots of unbroken phenocrysts with variable grain size (from $0.2-0.3$ to $0.4-0.5 \mathrm{~mm}$ ) yielded similar ${ }^{3} \mathrm{He}$ concentrations for all aliquots, while different grain sizes are likely to have contrasting magmatic helium contents. This observation supports the assumption of a very low magmatic helium correction. Consequently, we will use in the following discussion a constant magmatic ${ }^{3} \mathrm{He}$ correction of $6.7 \pm 6.7 \times 10^{5}$ at. $\mathrm{g}^{-1}$ for each TU8 aliquot. TU8 pyroxenes are thus suited for this study and will yield complementary informations to that obtained from MK9D olivines and pyroxenes. This will allow an independent test of the inter-sample reproducibility of our conclusions.

\subsubsection{Proton-irradiated olivines}

Proton-irradiated olivines were also used for several of our experiments because they have concentrations of matrix-sited ${ }^{3} \mathrm{He}$ about $10^{3}$ times above the natural samples MK9D and TU8. These samples are thus useful to (i) place limits on the fraction of helium released by vacuum crushing and (ii) perform new helium diffusion experiments using crushed minerals. The new diffusion data will allow us to assess if the crushing modifies helium diffusivity. One of the samples selected for irradiation is a gemquality $\mathrm{Fo}_{75}-\mathrm{Fo}_{80}$ olivine from a Guadalupe Island dunite (Batiza, 1977). The selected fragment was almost free of fluid inclusions and analyses of other olivines from this area indicate that the magmatic helium content of this material is several orders of magnitude lower than the proton-induced ${ }^{3} \mathrm{He}$ concentration (Shuster et al., 2004). This ensures that the magmatic ${ }^{3} \mathrm{He}$, which is contained within fluid inclusions, cannot bias the diffusion data obtained from the release pattern of the matrix-sited proton-induced ${ }^{3} \mathrm{He}$. The other irradiated olivine sample is a gem-quality $\mathrm{FO}_{92}$ crystal from xenoliths of San Carlos, Arizona (Frey and Prinz, 1976).
The Guadalupe olivine was irradiated in April 2002 under a fluence of $3.2 \times 10^{14}$ protons $\mathrm{cm}^{-2}$ over a 10 -h period with a $147-\mathrm{MeV}$ proton beam generated by a synchrocyclotron at Harvard Cyclotron Laboratory following the analytical conditions previously described in (Shuster et al., 2004). By contrast, the San Carlos olivine sample was irradiated in May 2007, under a fluence of $4.6 \times 10^{15}$ protons $\mathrm{cm}^{-2}$ with an energy of $220 \mathrm{MeV}$ at the Francis $\mathrm{H}$. Burr Proton Therapy Center of Massachusetts General Hospital.

\subsection{Experimental techniques}

\subsubsection{Crushing experiments}

2.2.1.1. Vacuum crushing. The purity of each aliquot of separated phenocrysts was carefully checked under a binocular microscope. Special attention was paid to remove any grains with adhering matrix. The starting size fraction of MK9D olivines and pyroxenes was $0.5-1 \mathrm{~mm}$. Because this grain size is smaller than the initial diameter of the original grains $(\sim 5 \mathrm{~mm})$, it is likely that some of the fluid inclusions were broken, releasing a fraction of their total magmatic helium. The $0.3-$ to $0.5-\mathrm{mm}$ fraction was processed in the case of the TU8 pyroxenes. In this diameter range, most of the grains were unbroken euhedral phenocrysts. Each phenocryst aliquot was weighed before being loaded in the crushing device (masses are listed in Table 1). Typical sample mass was $\sim 1$ g for samples with only natural helium (MK9D and TU8). Given the high amounts of proton-induced ${ }^{3} \mathrm{He}$, a small $(69 \mathrm{mg})$ single fragment of the San Carlos olivine was loaded in the crushing tube.

Online crushing was performed using stainless steel tubes in which magnetic slugs of $\sim 64 \mathrm{~g}$ are activated by three external solenoids. The slug used at Caltech is partially hollowed out over about $1 / 4$ of the cylinder, while the slug used at CRPG (Nancy) is a full steel cylinder. The crushing frequency was $\sim 60$ strokes per minute, with a delivered energy of $\sim 0.4 \mathrm{~J}$ per stroke. Because temperature is a crucial parameter controlling volume diffusion, the initial apparatus was slightly modified. For this, the tube was wrapped with a resistance heater tape and a thermocouple was attached at the bottom of the tube, where the sample resides. This design permitted us to measure $\left( \pm 10^{\circ} \mathrm{C}\right.$ ) and adjust (up to $325^{\circ} \mathrm{C}$ ) the temperature of the sample during crushing. While TU8 and San Carlos olivines were crushed under cold conditions $\left(T \sim 25^{\circ} \mathrm{C}\right)$, MK9D phenocrysts (both olivines and pyroxenes) were crushed at different temperatures (from 25 up to $325^{\circ} \mathrm{C}$ ). Sequential crushing (steps of 5,10 and $15 \mathrm{~min}$ ) was carried out to observe the evolution of ${ }^{3} \mathrm{He}$ and ${ }^{4} \mathrm{He}$ release through time. The helium released after each crushing step was purified over SAES getters, cryofocussed and separated from $\mathrm{Ne}$ according to the procedure used at Caltech (Patterson and Farley, 1998). Then, helium was inlet into a MAP 215-50 mass spectrometer and the two isotopes analyzed by peak-jumping, ${ }^{3} \mathrm{He}$ being counted on a pulse-counting electron multiplier and ${ }^{4} \mathrm{He}$ on a Faraday cup. Abundances were determined by peak height comparison with gas standards of known composition. Linearity of ${ }^{3} \mathrm{He}$ sensitivity 
Table 1

Helium data from in vacuo crushing experiment

\begin{tabular}{|c|c|c|c|c|c|c|c|c|c|}
\hline Sample & Mass (g) & $\begin{array}{l}\text { Crushing time } \\
(\mathrm{min})\end{array}$ & $\begin{array}{l}\text { Temperature } \\
\left({ }^{\circ} \mathrm{C}\right)\end{array}$ & $\begin{array}{l}{ }^{3} \mathrm{He} \\
\left(10^{5} \text { at. } \mathrm{g}^{-1}\right)\end{array}$ & $\begin{array}{l}{ }^{4} \mathrm{He} \\
\left(10^{10} \text { at. } \mathrm{g}^{-1}\right)\end{array}$ & $\begin{array}{l}{ }^{3} \mathrm{He} /{ }^{4} \mathrm{He} \\
(\mathrm{Ra})\end{array}$ & $\begin{array}{l}{ }^{4} \mathrm{He} \text { flux } \\
\left(10^{9} \text { at. } \mathrm{g}^{-1} \min ^{-1}\right)\end{array}$ & $\begin{array}{l}\text { Extracted } \\
{ }^{3} \mathrm{He}_{\text {cex }}{ }^{\mathrm{a}}\left(10^{5} \text { at. } \mathrm{g}^{-1}\right)\end{array}$ & $\begin{array}{l}\text { Fraction of } \\
\text { extracted }{ }^{3} \mathrm{He}_{\mathrm{c}}(\%)\end{array}$ \\
\hline $\begin{array}{l}\text { MK9D olivines } \\
0.5-1 \mathrm{~mm}\end{array}$ & 1.0 & $\begin{array}{r}5 \\
10 \\
15\end{array}$ & $\begin{array}{l}25 \\
25 \\
25\end{array}$ & $\begin{array}{l}7.1 \pm 0.2 \\
1.7 \pm 0.2 \\
0.4 \pm 0.2\end{array}$ & $\begin{array}{l}6.1 \pm 0.1 \\
1.4 \pm 0.1 \\
0.3 \pm 0.1\end{array}$ & $\begin{array}{l}8.4 \pm 0.3 \\
8.5 \pm 1.0 \\
8.7 \pm 4.7\end{array}$ & $\begin{array}{r}r 2.3 \pm 0.1 \\
1.4 \pm 0.1 \\
0.3 \pm 0.1\end{array}$ & $\begin{array}{r}<0.22 \\
0.03 \pm 0.2 \\
0.02 \pm 0.2\end{array}$ & $\begin{array}{l}0.0 \\
0.0 \\
0.0\end{array}$ \\
\hline Total & & 30 & & $9.1 \pm 0.3$ & $7.9 \pm 0.2$ & & & $0.04 \pm 0.4$ & 0.1 \\
\hline $\begin{array}{l}\text { MK9D olivines } \\
0.5-1 \mathrm{~mm}\end{array}$ & 1.4 & $\begin{array}{r}5 \\
10 \\
15\end{array}$ & $\begin{array}{l}300 \\
300 \\
325\end{array}$ & $\begin{array}{l}5.8 \pm 0.1 \\
2.7 \pm 0.1 \\
3.4 \pm 0.1\end{array}$ & $\begin{array}{l}4.9 \pm 0.1 \\
1.8 \pm 0.1 \\
1.2 \pm 0.1\end{array}$ & $\begin{array}{l}8.5 \pm 0.2 \\
10.9 \pm 0.5 \\
20.3 \pm 0.9\end{array}$ & $\begin{array}{l}9.8 \pm 0.1 \\
1.8 \pm 0.1 \\
0.8 \pm 0.1\end{array}$ & $\begin{array}{l}0.1 \pm 0.1 \\
0.6 \pm 0.1 \\
2.0 \pm 0.1\end{array}$ & $\begin{array}{l}0.1 \\
0.8 \\
2.4\end{array}$ \\
\hline Total & & 30 & & $11.8 \pm 0.2$ & $7.9 \pm 0.2$ & & & $2.7 \pm 0.2$ & 3.3 \\
\hline $\begin{array}{l}\text { MK9D pyroxenes } \\
0.5-1 \mathrm{~mm}\end{array}$ & 0.9 & $\begin{array}{r}5 \\
10 \\
15 \\
15\end{array}$ & $\begin{array}{l}300 \\
300 \\
300 \\
325\end{array}$ & $\begin{array}{l}1.3 \pm 0.2 \\
1.5 \pm 0.2 \\
2.2 \pm 0.2 \\
3.5 \pm 0.2\end{array}$ & $\begin{array}{l}1.4 \pm 0.1 \\
0.5 \pm 0.1 \\
0.3 \pm 0.1 \\
0.1 \pm 0.1\end{array}$ & $\begin{array}{l}6.5 \pm 0.9 \\
24 \pm 3 \\
59 \pm 9 \\
202 \pm 57\end{array}$ & $\begin{array}{l}2.8 \pm 0.1 \\
0.5 \pm 0.1 \\
0.3 \pm 0.1 \\
0.1 \pm 0.1\end{array}$ & $\begin{array}{l}<0.25 \\
1.1 \pm 0.2 \\
2.0 \pm 0.3 \\
3.4 \pm 0.3\end{array}$ & $\begin{array}{l}0.0 \\
1.4 \\
2.5 \\
4.3\end{array}$ \\
\hline Total & & 45 & & $8.6 \pm 0.4$ & $2.3 \pm 0.2$ & & & $6.5 \pm 0.4$ & 8.1 \\
\hline TU8 pyroxenes $0.3-0.5 \mathrm{~mm}$ & 0.6 & $\begin{array}{l}0.5 \\
3 \\
10\end{array}$ & $\begin{array}{l}25 \\
25 \\
25\end{array}$ & $\begin{array}{l}0.1 \pm 0.1 \\
0.3 \pm 0.1 \\
1.30 \pm 0.1\end{array}$ & $\begin{array}{l}0.5 \pm 0.1 \\
1.4 \pm 0.1 \\
4.7 \pm 0.1\end{array}$ & $\begin{array}{l}0.8 \pm 1.2 \\
1.5 \pm 0.5 \\
2.0 \pm 0.1\end{array}$ & $\begin{array}{r}11.0 \pm 0.6 \\
4.6 \pm 0.1 \\
4.7 \pm 0.1\end{array}$ & $\begin{array}{l}<0.24 \\
0.1 \pm 0.1 \\
0.8 \pm 0.2\end{array}$ & $\begin{array}{l}0.0 \\
0.1 \\
0.4\end{array}$ \\
\hline Total & & 13.5 & & $1.6 \pm 0.2$ & $6.7 \pm 0.2$ & & & $0.9 \pm 0.3$ & 0.5 \\
\hline $\begin{array}{l}\text { Irradiated } \\
\text { San Carlos } \\
\text { olivine } 1 \text { fragment }\end{array}$ & 0.069 & $\begin{array}{r}5 \\
10 \\
10\end{array}$ & $\begin{array}{l}25 \\
25 \\
25\end{array}$ & $\begin{array}{l}18,000 \pm 500 \\
20,100 \pm 600 \\
30,800 \pm 900\end{array}$ & $\begin{array}{l}1.7 \pm 0.1 \\
2.1 \pm 0.2 \\
2.8 \pm 0.2\end{array}$ & & $\begin{array}{l}0.36 \pm 0.01 \\
0.40 \pm 0.01 \\
0.31 \pm 0.01\end{array}$ & & $\begin{array}{l}0.5 \\
0.5 \\
0.8\end{array}$ \\
\hline Total & & 25 & & $68,900 \pm 1200$ & $6.6 \pm 0.4$ & & & & 1.8 \\
\hline
\end{tabular}

Crushing frequency is about 60 strokes per minute.

${ }^{3} \mathrm{He}_{\mathrm{cex}}$ is calculated from Eq. (3). 
was established by adjusting the standard size, so that the amount of ${ }^{4} \mathrm{He}$ in the mass spectrometer is similar for samples and standards (Burnard and Farley, 2000). Sensitivities were typically $\sim 1.7 \times 10^{-5}$ cps at. $^{-1}$ and $\sim 3 \times 10^{-7}$ $\mathrm{mV}$ at. ${ }^{-1}$ for ${ }^{3} \mathrm{He}$ and ${ }^{4} \mathrm{He}$, respectively. Uncertainties for the measured ${ }^{3} \mathrm{He}$ and ${ }^{4} \mathrm{He}$ concentrations included the internal reproducibility $(<1 \%)$, the external reproducibility computed from the analysis of standards $\left(3 \%\right.$ for ${ }^{3} \mathrm{He}$ and $1 \%$ for ${ }^{4} \mathrm{He}$ ), as well as the error attached to the blank correction. Because these sources of error are independent, a quadratic sum was made to calculate the total analytical uncertainty. All these uncertainties are here given at the $1 \sigma$ level. The crushing apparatus is designed to degas the tube activating the slug before dropping the samples. This capability permits measurement (and lowering of) the blanks before each analysis. ${ }^{3} \mathrm{He}$ and ${ }^{4} \mathrm{He}$ blanks were $3.6 \pm 0.6 \times 10^{3}$ and $3 \pm 1 \times 10^{8}$ atoms per minute, respectively. Because this background was not temperaturedependent but only time-dependent, similar blank corrections were used for both cold and hot experiments. ${ }^{3} \mathrm{He}$ blanks were between $4 \%$ and $34 \%$ of the gas extracted from the samples and ${ }^{4} \mathrm{He}$ blanks between $2 \%$ and $65 \%$ of the sample. The uncertainties associated with these blank estimates are $16 \%$ and $40 \%$ for ${ }^{3} \mathrm{He}$ and ${ }^{4} \mathrm{He}$, respectively, and this correction is thus the main source of uncertainty for these crushing analyses.

The characteristics (time and temperature) of these online crushing experiments are given in Table 2 for each sample. These results are used to assess the mechanisms controlling the release of the different helium components.

2.2.1.2. Crushing in an agate mortar. An aliquot of $\sim 1 \mathrm{~g}$ MK9D olivines was crushed in air, using an agate mortar and pestle. This was done in ethanol, to ensure that the sample was kept at low temperature $\left(\sim 25^{\circ} \mathrm{C}\right)$ and to inhibit grain ejection. The mechanisms involved in this kind of crushing are different (time of impact is longer, experiment is done in air) from those within the vacuum crushing device. This experiment was therefore carried out as a comparative test, in order to check if the ${ }^{3} \mathrm{He}_{\mathrm{c}}$ release is sensitive to the crushing conditions.

\subsubsection{Measurement of cosmogenic ${ }^{3}$ He concentrations}

Results from previous studies (Yokochi et al., 2005; Blard et al., 2006b) suggest that grain size is an important parameter controlling matrix-sited ${ }^{3} \mathrm{He}_{\mathrm{c}}$ release. Consequently, to assess grain size control on ${ }^{3} \mathrm{He}$ loss, the crushed samples were sieved into different granulometric fractions (from $<10$ to $>190 \mu \mathrm{m}$, see Table 2 for details). Fine $(<50 \mu \mathrm{m})$ steel chips originating from the crusher were removed from the phenocrysts using a hand magnet, to minimize contamination. Indeed, this metallic component, together with possible contamination from previous samples, may have very high helium content (more than $10^{14}{ }^{4} \mathrm{He}$ at. $\mathrm{g}^{-1}$, the ${ }^{3} \mathrm{He} /{ }^{4} \mathrm{He}$ ratio being $<0.02 \mathrm{Ra}$ ). After sieving, each fraction was carefully checked under a binocular microscope, to ensure that grains were not constituted of agglomerated smaller grains. The ${ }^{3} \mathrm{He}_{\mathrm{c}}$ content of each fraction was then measured by degassing in a double-walled vacuum fur- nace. Extraction temperature was set at $1500-1600{ }^{\circ} \mathrm{C}$ for $20 \mathrm{~min}$. For each sample, complete extraction yield was verified by a second heating step, which always yielded blank level helium. Measurement of ${ }^{3} \mathrm{He}$ and ${ }^{4} \mathrm{He}$ abundances was performed under similar conditions as those described in Section 2.2.1.1. Furnace hot blanks were $1.3 \pm 1.1 \times 10^{4}$ and $6.6 \pm 3 \times 10^{9}$ atoms for ${ }^{3} \mathrm{He}$ and ${ }^{4} \mathrm{He}$, respectively. These ${ }^{3} \mathrm{He}$ blanks were $<5 \%$ for most samples and do not represent a major source of uncertainty. In contrast, ${ }^{4} \mathrm{He}$ blanks were up to $100 \%$ of the ${ }^{4} \mathrm{He}$ extracted from the MK9D samples.

\subsubsection{Diffusion experiments}

Previous diffusion experiments (Trull et al., 1991; Trull and Kurz, 1993; Shuster et al., 2004) were performed using mafic phenocrysts that were not crushed intensely. It is unknown whether these results are also valid for minerals whose structure has suffered prolonged crushing such as the one experienced by the phenocrysts in the crushing apparatus. Consequently, we carried out new diffusion experiments using fragments of irradiated samples that were crushed under different conditions. Guadalupe olivine was crushed in air at low temperature $\left(25^{\circ} \mathrm{C}\right)$ using several hammer strokes. The resulting fragments were sieved and $0.59 \mathrm{mg}$ of $100-300 \mu \mathrm{m}$ grains were loaded in a diffusion cell (Farley et al., 1999). San Carlos olivine was crushed in vacuum in the tube, at low temperature $\left(25^{\circ} \mathrm{C}\right)$ and for $25 \mathrm{~min}$, under the conditions described in Section 2.2.1.1. After sieving, the grains were cleaned with ethanol to remove the adhering powder. $0.95 \mathrm{mg}$ of the $40-$ to $60-\mu \mathrm{m}$ fraction of this sample was loaded in a diffusion cell. After microscopic inspection we concluded that the shape of these crushed fragments was roughly spherical. Olivines were held at a known temperature $T_{i}$ during a time $t_{i}$ under static vacuum. At each heating step, released ${ }^{3} \mathrm{He}$ was purified (see Section 2.2.1.1) and measured by static mass spectrometry (MAP 215-50 and GV SFT). Maximum temperatures reached during diffusion experiments were 480 and $560{ }^{\circ} \mathrm{C}$ for San Carlos and Guadalupe olivine, respectively. After the diffusion experiment, samples were heated to $\sim 1600{ }^{\circ} \mathrm{C}$ in the furnace (described in Section 2.2.2) to determine the remaining ${ }^{3} \mathrm{He}$ content. Each heating step yielded between $1 \times 10^{4}$ and $2.9 \times 10^{7}$ at of ${ }^{3} \mathrm{He}$ (Table 3). With the exception of the first low temperature step, blank contribution $\left(1.2 \times 10^{4}\right.$ atoms $)$ was lower than $5 \%$ and the total relative uncertainty of the yield was from $3 \%$ to $5 \%$. The ${ }^{3} \mathrm{He}$ step-release fractions were converted into diffusion coefficients according to the analytical solutions of (Fechtig and Kalbitzer, 1966). To allow an absolute comparison between our results and the previous estimate, the measured diffusivities $\left(D / a^{2}\right)$ were converted into intrinsic diffusivities $(D)$ by dividing by the olivine grain radius, assuming that the physical grain equals the diffusion domain and that the geometry of the grains is spherical. For this computation a mass-weighted mean radius was computed for each sample, based on the analysis of the grain size distribution. This calculation yielded a weighted radius (a) of $123 \mu \mathrm{m}$ for the $100-$ to $300-\mu \mathrm{m}$ grains of the crushed Guadalupe 
Table 2

Cosmogenic ${ }^{3} \mathrm{He}$ data

\begin{tabular}{|c|c|c|c|c|c|c|}
\hline Sample & Grains size $(\mu \mathrm{m})$ & Mass (mg) & ${ }^{3} \mathrm{He}\left(10^{6}\right.$ at. $\left.\mathrm{g}^{-1}\right)$ & ${ }^{4} \mathrm{He}\left(10^{11}\right.$ at. $\left.\mathrm{g}^{-1}\right)$ & ${ }^{3} \mathrm{He}_{\mathrm{c}}{ }^{\mathrm{a}}\left(10^{6}\right.$ at. $\left.\mathrm{g}^{-1}\right)$ & Fraction of $\mathrm{He}_{\mathrm{c}}$ lost $(\%)$ \\
\hline \multicolumn{7}{|l|}{ Uncrushed samples } \\
\hline \multirow[t]{3}{*}{ MK9D olivines } & $500-1000$ & 258.5 & $8.94 \pm 0.20$ & $0.23 \pm 0.09$ & $8.66 \pm 0.22$ & \\
\hline & $500-1000$ & 218.4 & $8.04 \pm 0.19$ & $0.27 \pm 0.10$ & $7.71 \pm 0.22$ & \\
\hline & $500-1000$ & 224.0 & $8.40 \pm 0.19$ & $0.31 \pm 0.10$ & $8.02 \pm 0.23$ & \\
\hline Data from Blard et al., 2007 & $320-1000$ & 530.3 & $8.75 \pm 0.27$ & $0.21 \pm 0.04$ & $8.50 \pm 0.28$ & \\
\hline Weighted average $( \pm 1 \sigma)$ & & & $0.26 \pm 0.05$ & $8.23 \pm 0.27$ & & \\
\hline \multirow[t]{3}{*}{ MK9D proxenes } & $500-1000$ & 142.9 & $10.52 \pm 0.25$ & $1.61 \pm 0.16$ & $8.60 \pm 0.31$ & \\
\hline & $500-1000$ & 197.3 & $9.69 \pm 0.22$ & $1.27 \pm 0.11$ & $8.18 \pm 0.26$ & \\
\hline & $500-1000$ & 279.1 & $9.28 \pm 0.19$ & $1.29 \pm 0.08$ & $7.75 \pm 0.21$ & \\
\hline Data from Blard et al., 2007 & $150-1000$ & 565.4 & $9.14 \pm 0.25$ & $0.32 \pm 0.04$ & $8.76 \pm 0.26$ & \\
\hline Weighted average $( \pm 1 \sigma)$ & & & & $1.12 \pm 0.56$ & $8.24 \pm 0.29$ & \\
\hline \multicolumn{7}{|l|}{ Samples crushed at $25^{\circ} \mathrm{C}$} \\
\hline \multirow[t]{4}{*}{ MK9D olivines crushed in mortar at $25^{\circ} \mathrm{C}$} & $<40$ & 84.3 & $8.63 \pm 0.42$ & $1.26 \pm 0.26$ & $8.32 \pm 0.42$ & No loss \\
\hline & $40-65$ & 183.8 & $8.53 \pm 0.39$ & $0.77 \pm 0.12$ & $8.22 \pm 0.39$ & No loss \\
\hline & $65-105$ & 137.0 & $8.61 \pm 0.37$ & $0.73 \pm 0.16$ & $8.31 \pm 0.38$ & No loss \\
\hline & $105-190$ & 45.6 & $8.60 \pm 0.42$ & $0.64 \pm 0.49$ & $8.29 \pm 0.43$ & No loss \\
\hline \multirow[t]{4}{*}{ MK9D olivines crushed $30 \mathrm{~min}$ in tube at $25^{\circ} \mathrm{C}$} & $<10$ & 27.4 & $8.48 \pm 0.40$ & $4.35 \pm 0.81$ & $8.17 \pm 0.40$ & No loss \\
\hline & $10-40$ & 31.1 & $8.63 \pm 0.40$ & $4.11 \pm 0.71$ & $8.33 \pm 0.40$ & No loss \\
\hline & $40-75$ & 56.4 & $8.49 \pm 0.36$ & $5.06 \pm 0.39$ & $8.19 \pm 0.36$ & No loss \\
\hline & $125-1000$ & 34.0 & $9.12 \pm 0.42$ & $3.36 \pm 0.65$ & $8.82 \pm 0.43$ & No loss \\
\hline \multirow[t]{4}{*}{ TU8 pyroxenes crushed $13.5 \mathrm{~min}$ in tube at $25^{\circ} \mathrm{C}$} & $<45$ & 16.8 & $18.03 \pm 0.65$ & $630.6 \pm 1.6$ & $17.4 \pm 0.9$ & No loss \\
\hline & $45-65$ & 13.7 & $19.54 \pm 0.75$ & $718.8 \pm 1.9$ & $18.9 \pm 1.0$ & No loss \\
\hline & $65-105$ & 21.5 & $18.76 \pm 0.59$ & $262.9 \pm 1.1$ & $18.1 \pm 0.9$ & No loss \\
\hline & $>105$ & 54.7 & $19.07 \pm 0.47$ & $34.0 \pm 0.4$ & $18.4 \pm 0.8$ & No loss \\
\hline \multicolumn{7}{|l|}{ Samples crushed up to $325^{\circ} \mathrm{C}$} \\
\hline \multirow[t]{6}{*}{ MK9D olivines crushed $30 \mathrm{~min}$ in tube between 300 and $325^{\circ} \mathrm{C}$} & $<10$ & 32.7 & $6.83 \pm 0.36$ & $1.36 \pm 0.68$ & $6.53 \pm 0.37$ & 21 \\
\hline & $10-40$ & 58.3 & $7.86 \pm 0.30$ & $4.16 \pm 0.38$ & $7.55 \pm 0.31$ & 8 \\
\hline & $40-75$ & 127.9 & $8.50 \pm 0.30$ & $0.77 \pm 0.17$ & $8.20 \pm 0.31$ & No loss \\
\hline & $75-125$ & 51.5 & $8.60 \pm 0.33$ & $0.19 \pm 0.43$ & $8.29 \pm 0.33$ & No loss \\
\hline & $125-190$ & 79.7 & $8.16 \pm 0.30$ & $0.76 \pm 0.28$ & $7.86 \pm 0.31$ & No loss \\
\hline & $125-1000$ & 107.4 & $8.46 \pm 0.29$ & $0.15 \pm 0.21$ & $8.16 \pm 0.30$ & No loss \\
\hline MK9D pyroxenes crushed $45 \mathrm{~min}$ in tube between & $<10$ & 17.7 & $5.07 \pm 0.49$ & $1.53 \pm 1.26$ & $4.69 \pm 0.82$ & 43 \\
\hline \multirow{3}{*}{300 and $325^{\circ} \mathrm{C}$} & $10-40$ & 38.2 & $7.88 \pm 0.41$ & $9.77 \pm 0.58$ & $7.50 \pm 0.78$ & 9 \\
\hline & $40-75$ & 34.8 & $7.92 \pm 0.43$ & $5.13 \pm 0.64$ & $7.54 \pm 0.79$ & 8 \\
\hline & 104-190 & 19.5 & $8.72 \pm 0.67$ & $11.24 \pm 1.14$ & $8.35 \pm 0.94$ & No loss \\
\hline
\end{tabular}

${ }^{a}$ In the case of uncrushed MK9D phenocrysts, correction for magmatic ${ }^{3} \mathrm{He}$ is calculated assuming that (i) the individual ${ }^{4} \mathrm{He}$ concentrations measured in the same aliquot equal the magmatic ${ }^{4} \mathrm{He}$ and (ii) the magmatic ${ }^{3} \mathrm{He} /{ }^{4} \mathrm{He}$ ratio is $8 \mathrm{Ra}$. In the case of crushed MK9D phenocrysts, contamination by ${ }^{4} \mathrm{He}$-rich particles from the crushing tube is probable. So, correction for magmatic ${ }^{3} \mathrm{He}$ is computed using the weighted average of the ${ }^{4} \mathrm{He}$ measured within uncrushed phenocrysts and a magmatic ratio of 8 Ra. In the case of TU8 pyroxenes, magmatic correction is $6.7 \pm 6.7 \times 10^{5}$ at. $\mathrm{g}^{-1}$ of ${ }^{3} \mathrm{He}$ (see Section 2.1.1). 
Table 3

Diffusion data from Guadalupe and San Carlos crushed and irradiated olivines

\begin{tabular}{|c|c|c|c|c|}
\hline Temperature $\left({ }^{\circ} \mathrm{C}\right)$ & Time $(\mathrm{s})$ & ${ }^{3} \mathrm{He}\left(10^{5}\right.$ atoms $)$ & $10^{4} / T\left(\mathrm{~K}^{-1}\right)$ & $\ln D\left(\ln \left(\mathrm{cm}^{2} \mathrm{~s}^{-1}\right)\right)$ \\
\hline \multicolumn{5}{|c|}{ Crushed, irradiated Guadalupe olivine $100-300 \mu \mathrm{m}(0.59 \mathrm{mg})$. Equivalent weighted radius is 123 microns } \\
\hline 300 & 3600 & 3 & 17.5 & -30.4 \\
\hline 310 & 3600 & 1 & 17.2 & -30.6 \\
\hline 320 & 3600 & 1 & 16.9 & -30.4 \\
\hline 330 & 1800 & 1 & 16.6 & -29.9 \\
\hline 340 & 1800 & 1 & 16.3 & -29.5 \\
\hline 350 & 1800 & 1 & 16.1 & -29.0 \\
\hline 360 & 1800 & 2 & 15.8 & -28.7 \\
\hline 370 & 1800 & 2 & 15.6 & -28.4 \\
\hline 380 & 1800 & 2 & 15.3 & -28.0 \\
\hline 390 & 1800 & 3 & 15.1 & -27.7 \\
\hline 400 & 1800 & 3 & 14.9 & -27.4 \\
\hline 420 & 1800 & 5 & 14.4 & -26.6 \\
\hline 440 & 1800 & 8 & 14.0 & -25.9 \\
\hline 460 & 1800 & 10 & 13.6 & -25.4 \\
\hline 480 & 1800 & 12 & 13.3 & -24.9 \\
\hline 500 & 1800 & 16 & 12.9 & -24.3 \\
\hline 520 & 1800 & 20 & 12.6 & -23.9 \\
\hline 540 & 1800 & 24 & 12.3 & -23.4 \\
\hline 560 & 1800 & 28 & 12.0 & -23.0 \\
\hline
\end{tabular}

Total ${ }^{3} \mathrm{He}$ after fusion $\left(10^{5}\right.$ atoms $)$

769

Crushed, irradiated San Carlos olivine 40-60 $\mu \mathrm{m}$ (0.95 mg). Equivalent weighted radius is 26 microns

\begin{tabular}{|c|c|c|c|c|}
\hline 50 & 7200 & 0.1 & 31.0 & -45.2 \\
\hline 75 & 7200 & 0.2 & 28.7 & -42.4 \\
\hline 150 & 7200 & 1.1 & 23.6 & -39.1 \\
\hline 200 & 7200 & 3.4 & 21.1 & -36.6 \\
\hline 250 & 5400 & 14 & 19.1 & -33.6 \\
\hline 300 & 3600 & 38 & 17.5 & -31.0 \\
\hline 320 & 3600 & 38 & 16.9 & -30.3 \\
\hline 340 & 1800 & 28 & 16.3 & -29.6 \\
\hline 360 & 1800 & 47 & 15.8 & -28.7 \\
\hline 380 & 1800 & 65 & 15.3 & -28.0 \\
\hline 360 & 1800 & 17 & 15.8 & -29.2 \\
\hline 339 & 1800 & 5 & 16.3 & -30.3 \\
\hline 320 & 1800 & 2 & 16.9 & -31.4 \\
\hline 360 & 1800 & 12 & 15.8 & -29.4 \\
\hline 400 & 1800 & 61 & 14.9 & -27.7 \\
\hline 420 & 1800 & 104 & 14.4 & -26.9 \\
\hline 440 & 1800 & 149 & 14.0 & -26.2 \\
\hline 460 & 1800 & 248 & 13.6 & -25.3 \\
\hline 480 & 1800 & 288 & 13.3 & -24.8 \\
\hline
\end{tabular}

Total ${ }^{3} \mathrm{He}$ after fusion $\left(10^{5}\right.$ atoms $)$

3708

olivine and a radius of $28 \mu \mathrm{m}$ for the 40 - to $60-\mu \mathrm{m}$ grains of the crushed San Carlos olivine. The radius-normalized diffusivities $(D)$ were used together with the temperatures of each heating step to generate Arrhenius plots (Fig. 5). The activation energy $E_{\mathrm{a}}\left(\mathrm{J} \mathrm{mol}^{-1}\right)$ and the frequency factor $D_{0}\left(\mathrm{~cm}^{2} \mathrm{~s}^{-1}\right)$ were then estimated by linear regression, assuming an Arrhenius relationship:

$D(T)=D_{0} \cdot \exp \left(-E_{\mathrm{a}} / R T\right)$

where $R=8.314 \mathrm{~J} \mathrm{~K}^{-1} \mathrm{~mol}^{-1}$ is the gas constant. Temperature cycling was incorporated in the diffusion experiments carried out on the San Carlos sample, but not on the Guadalupe sample.

\section{RESULTS}

\subsection{Pattern of ${ }^{3} \mathrm{He}_{\mathrm{c}}$ release by vacuum crushing}

Helium data from the vacuum crushing experiments are summarized in Table 1 and Fig. 1.

In the case of the Hawaiian phenocrysts, all of the first crushing steps $\left(5 \mathrm{~min}\right.$ ) are characterized by ${ }^{3} \mathrm{He} /{ }^{4} \mathrm{He}$ ratios that are similar, within uncertainties, to the MORB-like reservoir value $\left(8 \mathrm{Ra}, \mathrm{Ra}=1.384 \times 10^{-6}\right.$ ) that was previously observed for these Mauna Kea lavas (Kurz et al., 1983; Eiler et al., 1996). This suggests that the magmatic component is dominant during this crushing step. We calculated the 


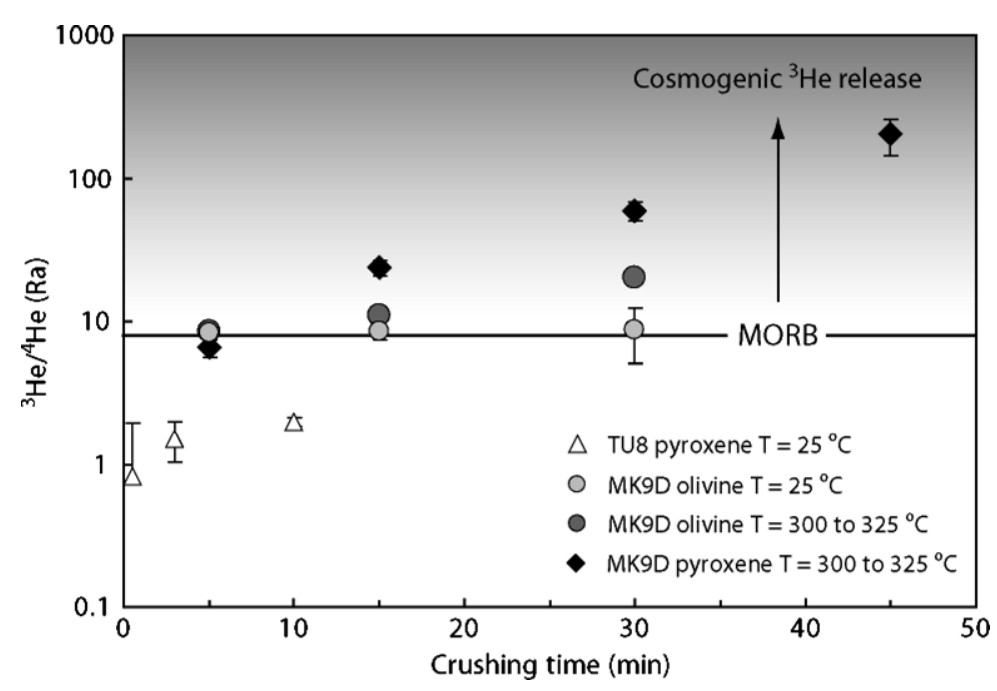

Fig. 1. Evolution of the measured ${ }^{3} \mathrm{He} /{ }^{4} \mathrm{He}$ ratio vs. time during step-crushing. Horizontal line shows the MORB-like value $\left(\mathrm{Ra}=1.384 \times 10^{-6}\right.$ is the air ${ }^{3} \mathrm{He} /{ }^{4} \mathrm{He}$ ratio $)$. Experiments were performed at various temperatures as indicated.

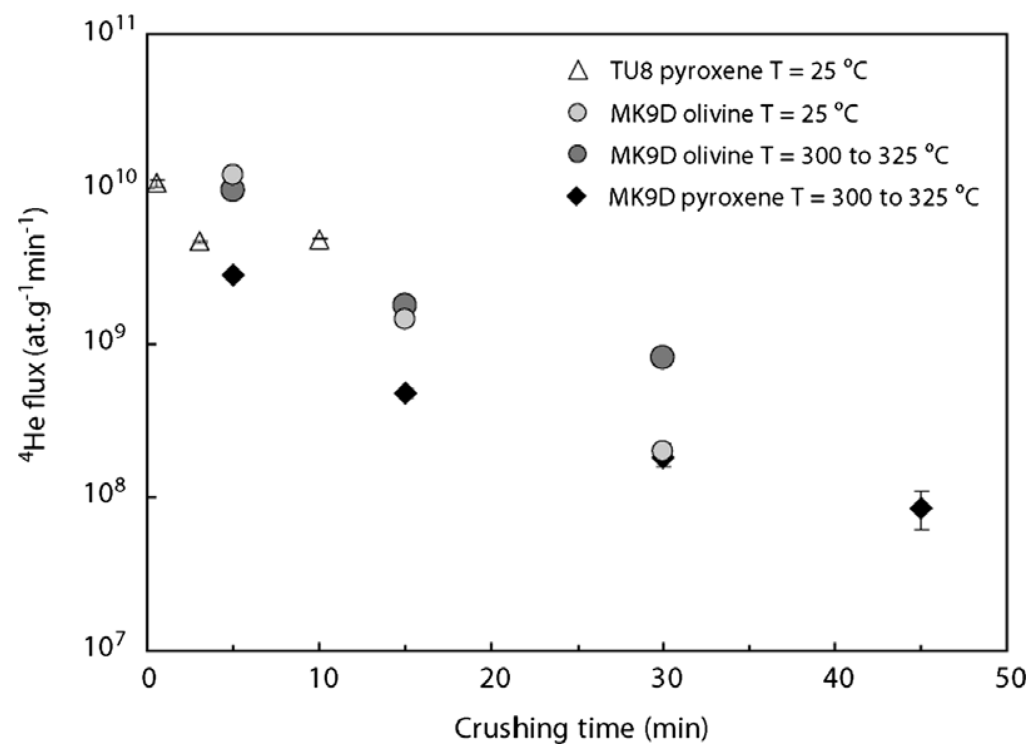

Fig. 2. Time evolution of the flux of ${ }^{4} \mathrm{He}$ released at each crushing step.

flux of helium extracted by crushing (Fig. 2). This was done following (Scarsi, 2000) by dividing the amount of released ${ }^{4} \mathrm{He}$ by the crushing time corresponding to each step. The first crushing steps are characterized by high ${ }^{4} \mathrm{He}$ fluxes (between $2.78 \pm 0.07$ and $12.29 \pm 0.07 \times 10^{9}$ at. $\mathrm{g}^{-1} \mathrm{~min}^{-1}$, Fig. 2), consistent with the order of magnitude observed by (Scarsi, 2000) under similar conditions and comparable magmatic concentrations. This author interpreted this primary and high-flux release as being characteristic of the activation of the magmatic helium reservoir, which actually corresponds to the helium component trapped within fluid or melt inclusions. Regardless of temperature, the flux of ${ }^{4} \mathrm{He}$ released during the subsequent crushing steps decrease with time. This decrease can be described by a simple exponential law (Fig. 2), which suggests, according to the model of (Scarsi, 2000), that ${ }^{4} \mathrm{He}$ has been extracted from a single reservoir (fluid inclusions), even after several minutes of crushing. This interpretation is consistent with the fact that concentration of matrix-sited radiogenic ${ }^{4} \mathrm{He}$ is quite low $\left(<3 \times 10^{9}\right.$ at. $\left.\mathrm{g}^{-1}\right)$ in MK9D phenocrysts. However, for crushing times greater than $5 \mathrm{~min}$ with $T>300^{\circ} \mathrm{C}$, the ${ }^{3} \mathrm{He} /{ }^{4} \mathrm{He}$ ratio measured from MK9D olivines and pyroxenes varies between $10.9 \pm 0.5$ and $202 \pm 58 \mathrm{Ra}$. This is far above the 8 -Ra MORB value (Table 1 and Fig. 1). Such ${ }^{3} \mathrm{He} /{ }^{4} \mathrm{He}$ ratios are higher than those previously reported for Mauna Kea basalts (Kurz et al., 1983; Eiler et al., 1996) and some of these values ( $>50 \mathrm{Ra})$ are even higher than the highest ratios observed for plume-like volcanism (Hilton et al., 1999; Stuart et al., 2003). Consequently, as previously observed by Yokochi et al. (2005) and Moreira and Madureira (2005) after several minutes of crushing, it seems inescapable that cosmogenic ${ }^{3} \mathrm{He}$ has been extracted 


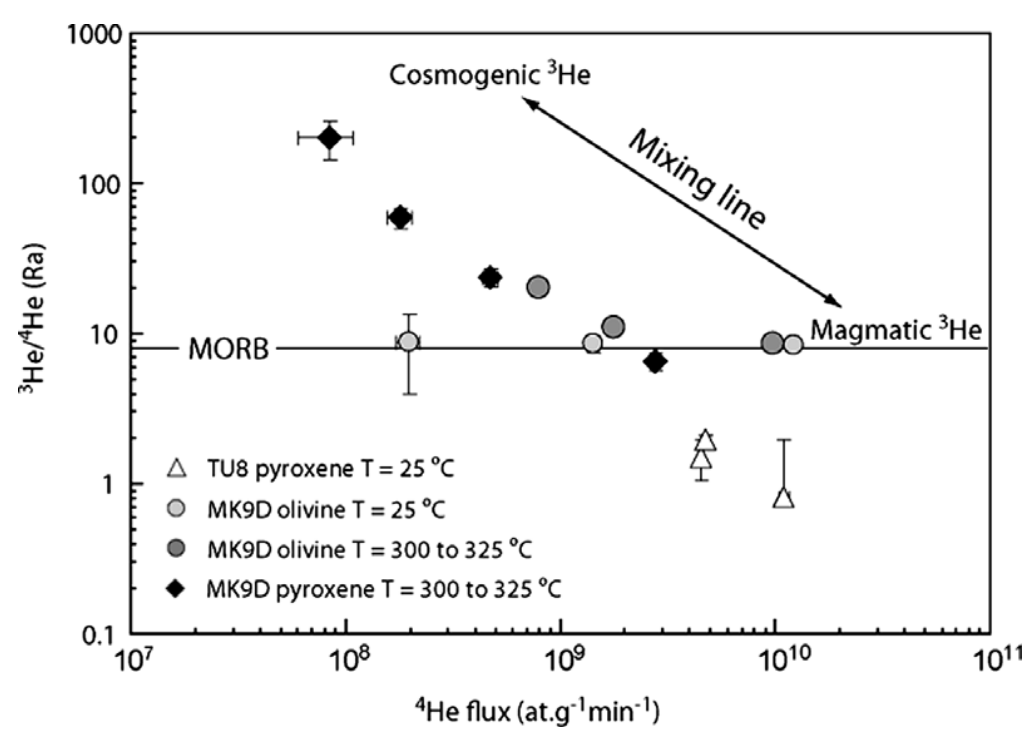

Fig. 3. Plot of the measured ${ }^{3} \mathrm{He} /{ }^{4} \mathrm{He}$ ratio against the corresponding flux of ${ }^{4} \mathrm{He}$ released by crushing. The anti-correlation obtained for MK9D phenocrysts crushed at high temperature can be interpreted as a mixing line between a pure magmatic helium reservoir and the addition of cosmogenic ${ }^{3} \mathrm{He}$. The measured ${ }^{3} \mathrm{He} /{ }^{4} \mathrm{He}$ is all the more sensitive to this addition of ${ }^{3} \mathrm{He}_{\mathrm{c}}$ as the flux of extracted ${ }^{4} \mathrm{He}$ is smaller.

from the phenocryst lattice. This conclusion is also supported by the anti-correlation between the measured ${ }^{3} \mathrm{He} /{ }^{4} \mathrm{He}$ ratios and the flux of extracted ${ }^{4} \mathrm{He}$ from samples crushed at $T>300{ }^{\circ} \mathrm{C}$ (Fig. 3). This empirical relationship reflects mixing between a magmatic helium component, having low ${ }^{3} \mathrm{He} /{ }^{4} \mathrm{He}$, and cosmogenic ${ }^{3} \mathrm{He}$, whose relative contribution to the crushed ${ }^{3} \mathrm{He} /{ }^{4} \mathrm{He}$ increases as the flux of magmatic ${ }^{4} \mathrm{He}$ is reduced (Fig. 3). Because the release of ${ }^{3} \mathrm{He}_{\mathrm{c}}$ is smallest during the short first crushing step (Yokochi et al., 2005), the best evaluation of the isotopic composition of the primordial (magmatic) trapped component is thus the $8.4 \pm 0.3 \mathrm{Ra}$ value obtained from the first crushing step of MK9D olivines (Table 1). Crushing steps of TU8 pyroxenes display ${ }^{3} \mathrm{He} /{ }^{4} \mathrm{He}$ ratios lower than the MORB value. (Scarsi, 2000) demonstrated that radiogenic ${ }^{4} \mathrm{He}$ may be easily extracted by vacuum crushing. Thus, because TU8 samples are rich in radiogenic ${ }^{4} \mathrm{He}$, these low ${ }^{3} \mathrm{He} /{ }^{4} \mathrm{He}$ ratios probably result from a two (or three) component mixture: magmatic helium, radiogenic ${ }^{4} \mathrm{He}$ (and cosmogenic $\left.{ }^{3} \mathrm{He}\right)$.

A helium budget calculation can be made to calculate the amount of ${ }^{3} \mathrm{He}_{\mathrm{c}}$ extracted at each step, using this assumed magmatic ${ }^{3} \mathrm{He} /{ }^{4} \mathrm{He}$ ratio $\left({ }^{3} \mathrm{He} /{ }^{4} \mathrm{He}\right.$ mag $)$ in this sample. Because radiogenic ${ }^{4} \mathrm{He}$ can be neglected compared to the magmatic ${ }^{4} \mathrm{He}$ component, the concentrations of cosmogenic ${ }^{3} \mathrm{He}$ extracted $\left({ }^{3} \mathrm{He}_{\mathrm{cex}}\right.$ in at. $\left.\mathrm{g}^{-1}\right)$ at each step is:

${ }^{3} \mathrm{He}_{\text {cex }}={ }^{4} \mathrm{He}_{\text {crush }} \times\left({ }^{3} \mathrm{He} /{ }^{4} \mathrm{He}_{\text {crush }}-{ }^{3} \mathrm{He} /{ }^{4} \mathrm{He}_{\text {mag }}\right)$

where ${ }^{4} \mathrm{He}_{\text {crush }}\left(\right.$ at. $\left.\mathrm{g}^{-1}\right)$ is the amount of ${ }^{4} \mathrm{He}$ and ${ }^{3} \mathrm{He} /$ ${ }^{4} \mathrm{He}_{\text {crush }}$ is the measured ${ }^{3} \mathrm{He} /{ }^{4} \mathrm{He}$ extracted at each step. $\left({ }^{3} \mathrm{He} /{ }^{4} \mathrm{He}_{\mathrm{mag}}\right)$ is assumed to be $8.4 \pm 0.3 \mathrm{Ra}$ for MK9D olivines, $6.5 \pm 0.9 \mathrm{Ra}$ MK9D pyroxenes, and $0.8 \pm 1.2 \mathrm{Ra}$ for TU8 pyroxenes.

In the $\geqslant 300{ }^{\circ} \mathrm{C}$ experiment, this calculation shows that the proportion of ${ }^{3} \mathrm{He}_{\mathrm{c}}$ lost in each step ranges from $1.4 \%$ to $4.3 \%$ for MK9D pyroxenes and between $0.1 \%$ and
$2.4 \%$ for MK9D olivines (Table 1). The sums of these losses represent total releases of $3.3 \%$ and $8.1 \%$, for MK9D olivines and pyroxenes, respectively. Such values are comparable with the order of magnitude of ${ }^{3} \mathrm{He}_{\mathrm{c}}$ loss observed by (Yokochi et al., 2005; Blard et al., 2006b), but are significantly above the $<0.5 \%$ loss reported by (Moreira and Madureira, 2005).

In contrast, the step-crushing performed on MK9D olivines under cold conditions $\left(T<25^{\circ} \mathrm{C}\right)$ does not show any increase of the ${ }^{3} \mathrm{He} /{ }^{4} \mathrm{He}$ ratio, remaining similar to the $8 \mathrm{Ra}$ MORB value, within uncertainties, even after $30 \mathrm{~min}$ of crushing (Table 1, Figs. 1 and 3). Consequently, MK9D olivines, as well as TU8 pyroxenes, released low amounts of ${ }^{3} \mathrm{He}_{\text {cex }}(<1 \%)$ in cold conditions, although the duration of crushing was similar to the experiment performed at high temperature (Table 1).

Moreover, given that the irradiated San Carlos olivine contains a very high concentration of matrix-sited ${ }^{3} \mathrm{He}$, crushing data obtained from this sample permits a very low detection limit of the ${ }^{3} \mathrm{He}$ loss. These data from San Carlos (Table 1) permit to place a maximum limit of $1.8 \%$ (for $30 \mathrm{~min}$ of crushing, i.e. $\sim 1800$ strokes) on the magnitude of the loss, under cold conditions $\left(T<25^{\circ} \mathrm{C}\right)$. This value is not significantly different from the ${ }^{3} \mathrm{He}_{\mathrm{c}}$ loss observed in the non-irradiated samples crushed under the same conditions.

\subsection{Cosmogenic ${ }^{3} \mathrm{He}$ concentrations vs. grain size}

The ${ }^{3} \mathrm{He}$ concentrations measured in the six aliquots of uncrushed MK9D olivines and pyroxenes subjected to total thermal outgassing ranged between $8.0 \pm 0.2 \times$ $10^{6}$ and $10.5 \pm 0.3 \times 10^{6}$ at. $\mathrm{g}^{-1}$. These minerals have contrasting ${ }^{4} \mathrm{He}$ concentrations that range between $0.2 \pm$ $0.1 \times 10^{11}$ and $0.3 \pm 0.1 \times 10^{11}$ at. $\mathrm{g}^{-1}$ for olivines and between $1.3 \pm 0.2 \times 10^{11}$ and $1.6 \pm 0.2 \times 10^{11}$ at. $\mathrm{g}^{-1}$ for 
pyroxenes. For each replicate, magmatic ${ }^{3} \mathrm{He}$ was calculated multiplying the ${ }^{4} \mathrm{He}$ concentration by the ${ }^{3} \mathrm{He} /{ }^{4} \mathrm{He}$ ratios measured from the first crushing step, i.e. $8.4 \pm$ $0.3 \mathrm{Ra}$ for olivines and $6.5 \pm 0.9 \mathrm{Ra}$ for pyroxenes. Cosmogenic ${ }^{3} \mathrm{He}$ concentrations of each uncrushed replicate were then calculated by difference. Resulting ${ }^{3} \mathrm{He}_{\mathrm{c}}$ concentrations agree within $1 \sigma$ and are consistent with the previous estimate of (Blard et al., 2007). Assuming that the absolute calibrations of the Caltech and the CRPG mass spectrometers match within analytical uncertainties, it is possible to use all these ${ }^{3} \mathrm{He}_{\mathrm{c}}$ data to calculate uncertainty weighted averages of $8.23 \pm 0.27 \times 10^{6}$ and $8.24 \pm 0.29 \times$ $10^{6}$ at. $\mathrm{g}^{-1}$ for olivines and pyroxenes, respectively. Because uncrushed phenocrysts have not been affected by ${ }^{3} \mathrm{He}_{\mathrm{c}}$ loss, these values will be considered in the following as reference concentrations to which the concentrations measured in the crushed samples will be compared.

Surprisingly, the ${ }^{4} \mathrm{He}$ concentrations measured in the furnace in the crushed phenocrysts are significantly above the average concentrations obtained from the uncrushed phenocrysts. This discrepancy is roughly anti-correlated with grain size (Table 2), and this observation is in contradiction with the fact that small crushed phenocrysts (typically $<100 \mu \mathrm{m})$ are depleted in inclusion-hosted magmatic helium (Kurz et al., 1990). Consequently, it seems reasonable to propose that the crushed phenocrysts were contaminated by small amounts of steel chips from the crushing tube that were not completely removed by the hand magnet separation. Indeed, given the high concentration of ${ }^{4} \mathrm{He}$ contained within these small pieces of steel $\left(>10^{14}\right.$ ${ }^{4} \mathrm{He}$ at. $\mathrm{g}^{-1}$ ), even few micrograms of material are sufficient to bias significantly the measured ${ }^{4} \mathrm{He}$ concentrations. Because the contaminating steel chips are fine $(<50 \mu \mathrm{m})$, this undesirable bias is all the more significant for the smallest fractions that were enriched in this contaminant through the sieving process. In addition, the furnace blanks were also a major source of uncertainty in estimating the concentration of ${ }^{4} \mathrm{He}$ of the smallest MK9D aliquots $(<100 \mathrm{mg})$, because these blank corrections represent up to $65 \%$ of the gas extracted from these samples. These considerations imply that the individual ${ }^{4} \mathrm{He}$ contents measured in the crushed phenocrysts will yield inaccurate ${ }^{3} \mathrm{He}_{\mathrm{c}}$ concentrations if they were used to correct for the magmatic ${ }^{3} \mathrm{He}$ (see Eq. (1)).

Consequently, we have chosen to estimate the magmatic ${ }^{3} \mathrm{He}$ correction for the crushed MK9D phenocrysts in a different way: we used the average magmatic concentrations obtained by fusing the uncrushed phenocrysts $\left(2.9 \pm 0.6 \times 10^{5}\right.$ and $1.2 \pm 0.6 \times 10^{6}$ at. $g^{-1}$ for olivines and pyroxenes, respectively, Table 1). For further comparison, it must be kept in mind that this estimate of the magmatic ${ }^{3} \mathrm{He}$ yields a maximum correction. In the case of the TU8 pyroxenes, correction for magmatic helium was performed assuming all the replicates have ${ }^{3} \mathrm{He}$ concentrations of $6.7 \pm 6.7 \times 10^{5}$ at. $\mathrm{g}^{-1}$ (see Section 2.1.1 for explanation). We stress that the standard magmatic ${ }^{3} \mathrm{He}$ correction should ideally be applied, especially when the crushing device is clean enough to prevent any helium contamination. This however high- lights how important it is to pay careful attention to the crushing conditions.

The corrected ${ }^{3} \mathrm{He}_{\mathrm{c}}$ concentrations show that the only samples that have been affected by loss that is statistically significant (outside $2 \sigma$ uncertainty) are the smallest fractions $(<10 \mu \mathrm{m})$ of MK9D olivines $(21 \%)$ and pyroxenes $(43 \%)$ that were crushed under hot conditions $\left(T>300^{\circ} \mathrm{C}\right)$ (Table 2 and Fig. 4). All samples crushed under cold conditions $\left(T<25^{\circ} \mathrm{C}\right)$, in the tube or the agate mortar, have ${ }^{3} \mathrm{He}_{\mathrm{c}}$ concentrations that are identical with the reference value, within $1 \sigma$ uncertainties, regardless of the duration and style of crushing (tube or mortar) (Table 2 and Fig. 4). These results are consistent with the observations from online crushing. These data support the conclusion that significant ${ }^{3} \mathrm{He}_{\mathrm{c}}$ loss only affects the smallest fraction and only if the sample is heated to sufficiently high temperatures $\left(T>300^{\circ} \mathrm{C}\right)$.

Furthermore, it is possible to perform a ${ }^{3} \mathrm{He}_{\mathrm{c}}$ budget calculation weighting the ${ }^{3} \mathrm{He}_{\mathrm{c}}$ concentration measured in each fraction by the mass of the corresponding sieve fraction. This estimate must be considered with caution because it assumes that the sieving has not changed the size distribution of the sample, while very fine fractions could have been lost during this process. The total ${ }^{3} \mathrm{He}_{\mathrm{c}}$ losses are $3 \pm 1 \%$ for M9D olivines and $13 \pm 8 \%$ for MK9D pyroxenes, which is consistent with the total loss observed from the online crushing (Table 1). Therefore, the good match between this budget and the data supports the view that the total ${ }^{3} \mathrm{He}_{\mathrm{c}}$ released by crushing the bulk fraction at $300{ }^{\circ} \mathrm{C}$ is mainly controlled by loss affecting the fraction $<10 \mu \mathrm{m}$, even when the loss from the bulk fraction is significant $(>10 \%)$

\subsection{Diffusivity of matrix-sited ${ }^{3} \mathrm{He}$ in crushed olivines}

The results of the two diffusion experiments are summarized in Table 3 and shown in Fig. 5 as Arrehnius plots $\left(\ln D\right.$ vs. $\left.10^{4} / T\right)$. The regression parameters of the best fit and the resulting diffusion parameters are summarized in Table 4.

Small ${ }^{3} \mathrm{He}$ excesses were observed relative to linearity during the initial and low-temperature $\left(T<100^{\circ} \mathrm{C}\right)$ steps. Because this release is within the blank level and can bias the estimated diffusivity, the points with this initial excess were removed before reducing these diffusion data. After removal of this excess, the data yield a linear correlation within the $\ln D$ vs $1 / T$ space for steps between 250 and $560{ }^{\circ} \mathrm{C}$. The retrograde cycling experiment performed on the San Carlos olivine exhibits a slight scatter around the regressed line (Fig. 5), but this remains lower than the inter-sample variability and should not represent a major limitation for the first order assessment that we want to perform here.

These experiments yielded activation energies $\left(E_{\mathrm{a}}\right)$ of $127 \pm 1$ and $127 \pm 6 \mathrm{~kJ} \mathrm{~mol}^{-1}$ and the frequency factors (given as $\ln D_{0}$ ) of $-4.65 \pm 0.02$ and $-4.8 \pm 0.7 \mathrm{~cm}^{2} \mathrm{~s}^{-1}$ for the Guadalupe and San Carlos olivines, respectively (Table 4). Similarities and discrepancies with previous determination are discussed below in Section 4.2. 

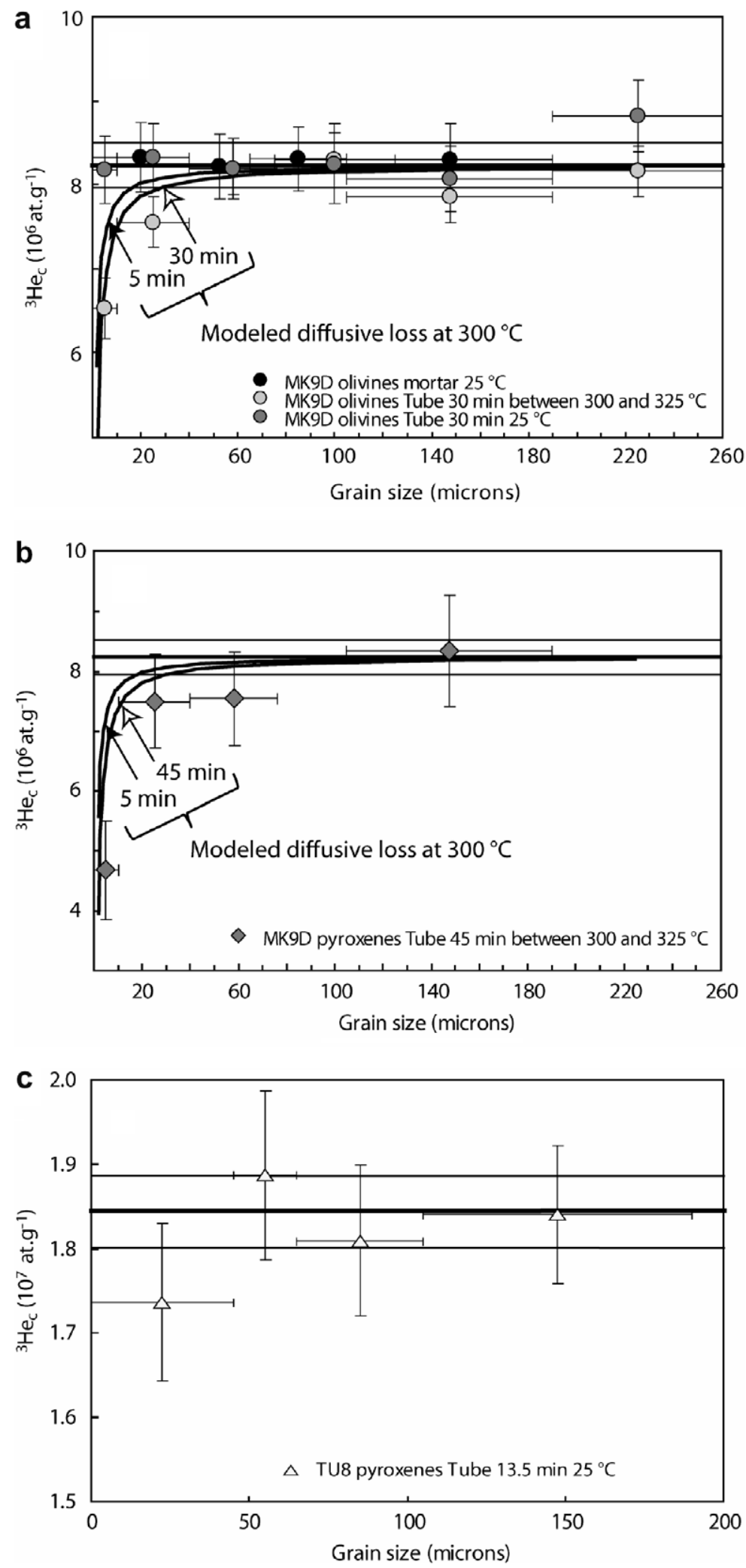

Fig. 4. Plot of the measured ${ }^{3} \mathrm{He}$ concentration vs. the grain diameter for (a) MK9D olivines, (b) MK9D pyroxenes and (c) TU8 pyroxenes. Horizontal lines are the average and the $1 \sigma$ envelop of the ${ }^{3} \mathrm{He}_{\mathrm{c}}$ concentrations determined from uncrushed phenocrysts. Black curves show the modeled diffusive loss for two extreme crushing times at $300{ }^{\circ} \mathrm{C}(5$ and $30 \mathrm{~min}$ of heating for MK9D olivines; 5 and 45 min of heating for MK9D pyroxenes). This was done because the time of apparition of the small fraction during crushing is uncertain. This modeling was done assuming grains have spherical geometry, using the diffusion coefficient established in the present study (Table 4) and the diffusion equation of (Fechtig and Kalbitzer, 1966). 


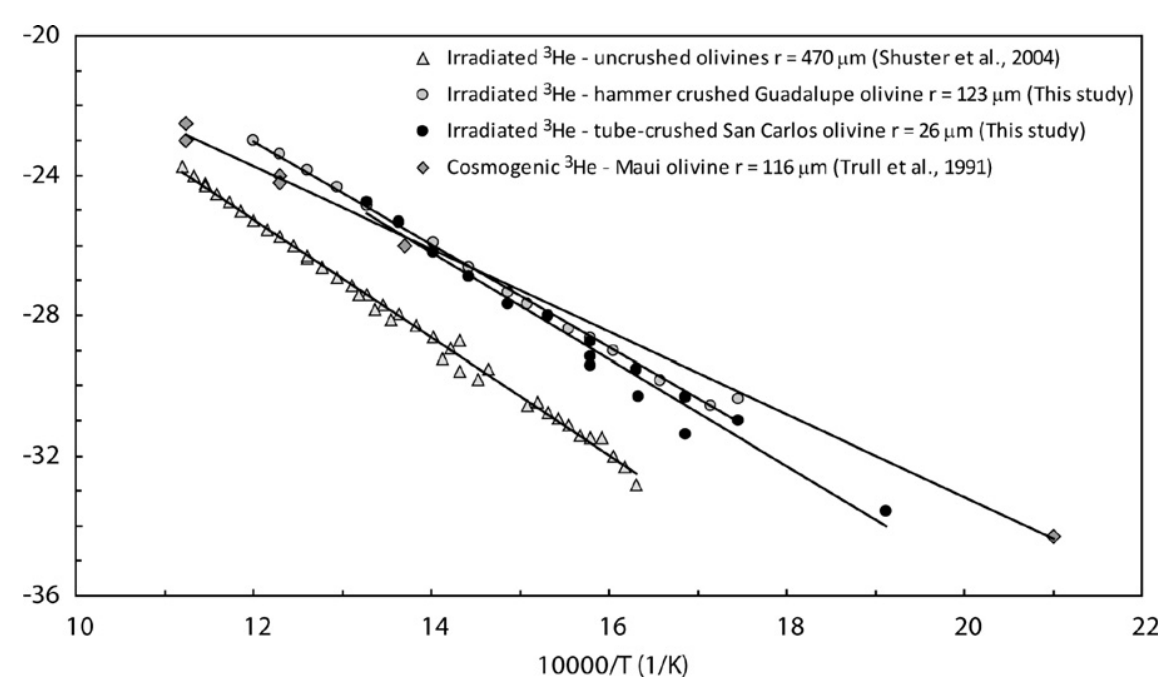

Fig. 5. Arrhenius plot from the diffusion experiment performed on the crushed Guadalupe and San Carlos olivines (this study). Also shown are the data of (Shuster et al., 2004) from irradiated uncrushed Guadalupe olivines and the data of (Trull et al., 1991) from Maui olivines exposed to cosmic rays. The diffusion coefficients obtained from these regressed data are given in Table 4 .

Table 4

Diffusion coefficients obtained for matrix-sited ${ }^{3} \mathrm{He}$ in olivines

\begin{tabular}{|c|c|c|c|c|c|c|c|}
\hline Reference & He variety & Sample & Crushed/uncrushed & $\begin{array}{l}\text { Radius }^{\mathrm{a}} \\
(\mu \mathrm{m})\end{array}$ & $R^{2}$ & $\begin{array}{l}\ln \left(D_{0}\right)(\ln \\
\left(\mathrm{cm}^{2} \mathrm{~s}^{-1}\right)\end{array}$ & $\begin{array}{l}E_{\mathrm{a}} \\
\left(\mathrm{kJ} \mathrm{mol}^{-1}\right)\end{array}$ \\
\hline $\begin{array}{l}\text { Shuster et al. } \\
(2004)\end{array}$ & $\begin{array}{l}\text { Irradiated } \\
{ }^{3} \mathrm{He}\end{array}$ & $\begin{array}{l}\text { Guadalupe olivine-- } \\
\mathrm{Fo}_{75-80}\end{array}$ & Uncrushed & 470 & 0.99 & $-5.1 \pm 0.3$ & $140 \pm 2$ \\
\hline $\begin{array}{l}\text { Trull et al. } \\
\text { (1991) }\end{array}$ & $\begin{array}{l}\text { Cosmogenic } \\
{ }^{3} \mathrm{He}\end{array}$ & Maui olivine-Fo $\mathrm{Fo}_{80}$ & Uncrushed & 116 & 0.99 & $-8.5 \pm 1.8$ & $105 \pm 17$ \\
\hline This study & $\begin{array}{l}\text { Irradiated } \\
{ }^{3} \mathrm{He}\end{array}$ & $\begin{array}{l}\text { Guadalupe olivine-- } \\
\mathrm{Fo}_{75-80}\end{array}$ & $\begin{array}{l}\text { Crushed in air three } \\
\text { hammers strokes }\end{array}$ & 123 & 0.99 & $-4.65 \pm 0.02$ & $127 \pm 1$ \\
\hline This study & $\begin{array}{l}\text { Irradiated } \\
{ }^{3} \mathrm{He}\end{array}$ & $\begin{array}{l}\text { San Carlos olivine-- } \\
\text { Fo }_{92}\end{array}$ & $\begin{array}{l}\text { Crushed in vacuo } 25 \mathrm{~min} \\
\text { in tube }\end{array}$ & 26 & 0.97 & $-4.8 \pm 0.7$ & $127 \pm 6$ \\
\hline
\end{tabular}

${ }^{\text {a }}$ Radii are given as equivalent sphere radii.

\section{DISCUSSION}

\subsection{Is the ${ }^{3} \mathrm{He}_{\mathrm{c}}$ crushing loss mainly the result of volume diffusion?}

These new experiments show that the ${ }^{3} \mathrm{He}_{\mathrm{c}}$ loss during vacuum crushing is not uniquely controlled by the grain size of the crushed phenocrysts, because even the smallest fraction $(<10 \mu \mathrm{m})$ did not show significant release under cold conditions $\left(T<25^{\circ} \mathrm{C}\right)$. This result is in contradiction with the previously proposed mechanism that involved spallation tracks, which are $10-$ to $20-\mu \mathrm{m}$-long matrix damage tracks induced by cosmogenic reactions (Finkel et al., 1978; Yokochi et al., 2005). This hypothesis assumes that any atom of ${ }^{3} \mathrm{He}_{\mathrm{c}}$ located in such a lattice defect would be released when the track encounters a new surface created by crushing. The relative loss induced by this theoretical mechanism is purely a function of the surface/volume ratio, and, is thus only dependent on the grain size. According to Yokochi et al. (2005), this model is not supposed to be temperature-dependent, and predicts that the loss would be at least $30 \%$ for fractions smaller than $30 \mu \mathrm{m}$, whatever the temperature and the crushing energy. Consequently, on the basis of our new data set, it seems reasonable to conclude that the model involving spallation tracks is invalid.

On the other hand, the results clearly show that detectable ${ }^{3} \mathrm{He}_{\mathrm{c}}$ loss occurs, but only in the smallest grain fraction and when the sample has been heated to $\geqslant 300^{\circ} \mathrm{C}$ (Table 2 and Fig. 4). This observation could be questioned on the ground that our magmatic ${ }^{3} \mathrm{He}$ correction (see Section 3.2) may overestimate the actual magmatic helium concentration of the finest phenocrysts. However, this possibility can be ruled out because, even if we make no magmatic correction, the loss remains significant, at the $1 \sigma$ level for the 10- to $40-\mu \mathrm{m}$ fraction of olivines, and at the $2 \sigma$ level for the $<10 \mu \mathrm{m}$ fractions of olivines and pyroxenes (Table 2). The concentration patterns observed in Fig. 4 are hence robust and representative of the characteristics of the crushing loss.

It appears that the ${ }^{3} \mathrm{He}_{\mathrm{c}}$ loss is controlled both by (i) the grain size and by (ii) the temperature and duration of the heating. Such behavior is characteristic of volume diffusion. To quantitatively assess this possibility, we modeled the magnitude of pure diffusion-driven loss as a function of grain size and temperature (Fig. 4). This theoretical loss was calculated assuming a spherical geometry of the grains 
and using the analytical solution from (Fechtig and Kalbitzer, 1966) with the temperature monitored during the crushing (Table 1) and the new empirical diffusion parameters ( $D_{0}$ and $E_{\mathrm{a}}$, Table 4 ) obtained in this study. Because the time at which the finest grains appears during crushing is uncertain, we considered two scenarios with extreme durations (from 5 to $30 \mathrm{~min}$ for olivines and from 5 to $45 \mathrm{~min}$ for pyroxenes, see Fig. 4 caption) to provide conservative upper and lower limits on the modeled magnitude of loss. The modeled loss matches the data fairly well, within $1 \sigma$ analytical uncertainties, and this consistency is thus a good argument in favor of a pure temperature-induced diffusive control of the ${ }^{3} \mathrm{He}_{\mathrm{c}}$ release during crushing. Diffusivity of magmatic helium can be significantly different in olivines and pyroxenes (Trull and Kurz, 1993). However, the diffusion kinetics of radiogenic ${ }^{4} \mathrm{He}$ in pyroxene (Lippolt and Weigel, 1988) is similar (within the same order of magnitude) to those obtained in this study from irradiated olivines (Fig. 6). Consequently, because we did not get diffusion data from irradiated clinopyroxene, we decided to use identical diffusion parameters (from irradiated olivines) to model the loss for both mineral species. The good agreement between the modeled and observed loss in MK9D pyroxenes (Fig. 4) suggests that diffusivity must be within the same order of magnitude for both minerals. Hence, this approximation is not a major source of uncertainty.

The hypothesis of purely diffusive control of ${ }^{3} \mathrm{He}_{\mathrm{c}}$ loss was ruled out by previous studies (Moreira and Madureira, 2005; Yokochi et al., 2005; Blard et al., 2006b), on the basis that, even if the highest empirical diffusion parameters were considered (Trull et al., 1991; Shuster et al., 2004), the calculated loss would be significantly lower than the observed ${ }^{3} \mathrm{He}_{\mathrm{c}}$ release. If the new diffusion parameters obtained here are considered and if we assume a similar grain size distribution as the one obtained here, the diffusion-induced loss would be about $0.5 \%$ for a bulk sample crushed at $70{ }^{\circ} \mathrm{C}$. This is consistent with the release observed by (Moreira and Madureira, 2005) at this temperature. However, these authors argue that the ${ }^{3} \mathrm{He} /{ }^{21} \mathrm{Ne}$ ratio measured during crushing is similar to the ratio of the olivine matrix, and this observation does not support a diffusion control of the crushing release given that helium diffusivity is several order of magnitude higher than the neon diffusivity (Shuster and Farley, 2005). Consequently, this observation implies that other mechanisms than diffusion cannot be totally ruled out. The fact that alternative mechanisms may also play a role is supported by the fact that $1.8 \%$ of matrix-sited ${ }^{3} \mathrm{He}$ was released by crushing under cold conditions the irradiated San Carlos olivine during $25 \mathrm{~min}$. Previous studies (Yokochi et al., 2005) and (Moreira and Madureira, 2005) proposed that extraction at the grain surface due to lattice distortion might be caused by plastic deformation during crushing. If this alternative mechanism could account for $\sim 1 \%$ of the extraction, the experimental results obtained in this study suggest that temperature-enhanced diffusion is the mechanism responsible for the increase of the level of ${ }^{3} \mathrm{He}_{\mathrm{c}}$ extraction above $10 \%$ (Table 2 and Fig. 3). Although each of these mechanisms is characterized by a different magnitude of ${ }^{3} \mathrm{He}_{\mathrm{c}}$ release, the coexis-

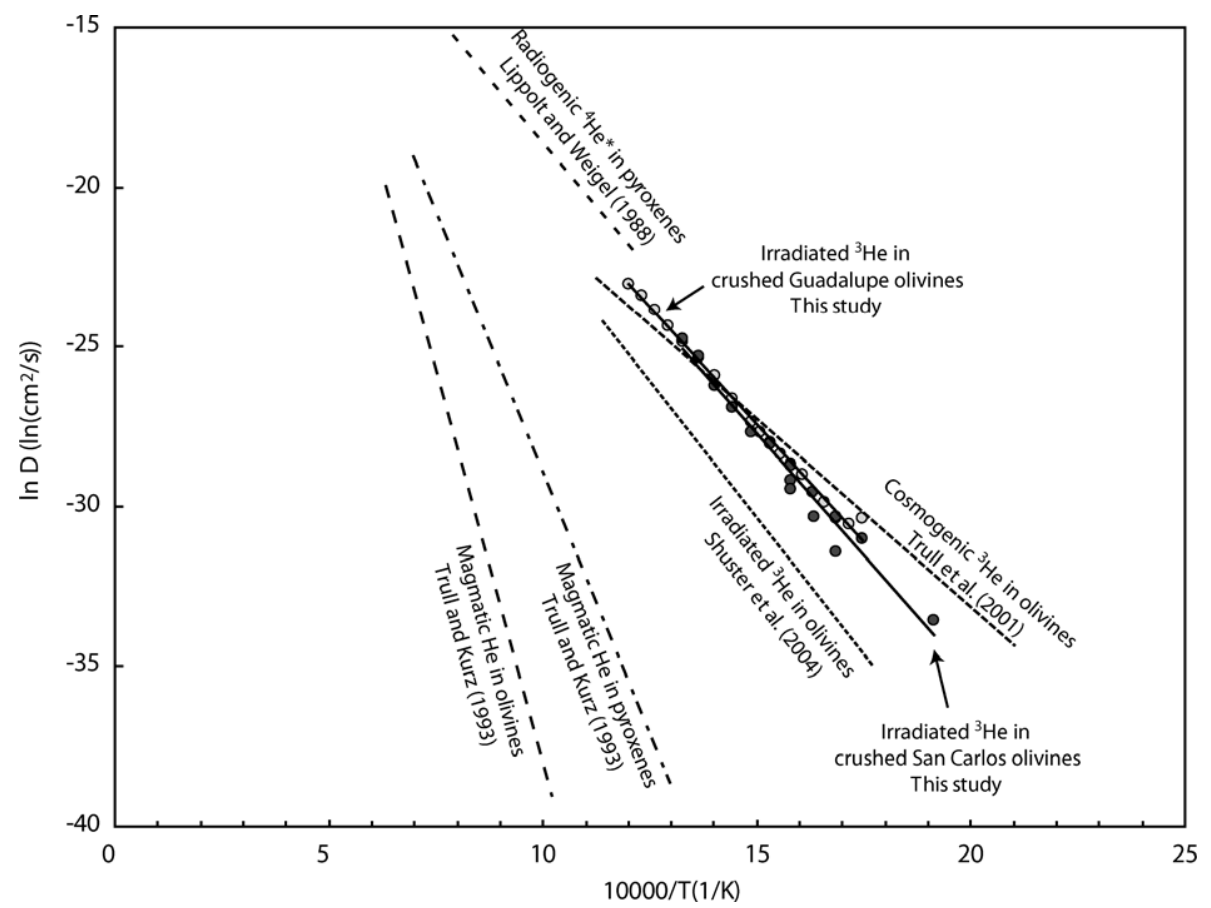

Fig. 6. Comparison of different Arrhenius diagrams for helium diffusivity in olivine. Diffusion data from (Trull and Kurz, 1993) are from inclusion-sited magmatic helium in olivine and pyroxenes. (Lippolt and Weigel, 1988) measured diffusivity of radiogenic ${ }^{4} \mathrm{He}$ in augite. Shuster et al. (2004) determined diffusion parameters for matrix-sited ${ }^{3} \mathrm{He}$ in irradiated olivines. Trull et al. (1991) measured the diffusivity of cosmogenic ${ }^{3} \mathrm{He}$ from olivines exposed to cosmic rays during $\sim 500 \mathrm{ka}$ at $\sim 3000 \mathrm{~m}$ elevation. Shown data from the present study were obtained from proton-irradiated olivines that were subsequently crushed (Fig. 5 and Table 4). 
tence of both is compatible with our observations and those of (Moreira and Madureira, 2005) and (Scarsi, 2000).

Nevertheless, it must be acknowledged that, even if our diffusion parameters are used, volume diffusion remains insufficient to reproduce the magnitude of losses of about $10-25 \%$ (from bulk fractions) that were observed by crushing olivines at the CRPG (Nancy) noble gas laboratory (Yokochi et al., 2005; Blard et al., 2006b). Indeed, considering the tube temperature $\left(T<100{ }^{\circ} \mathrm{C}\right)$ reported in these studies and the grain size distribution of the crushed samples (Yokochi et al., 2005; Blard et al., 2006b), diffusion would induce a loss $<1 \%$, far below the magnitude actually observed. Consequently it seems difficult to state that volume diffusion was the sole factor controlling the loss observed at the CRPG laboratory. Other mechanisms responsible for the loss could also be specific to the CRPG crushing apparatus, such as short-term increase of diffusivity caused by plastic deformation (Yokochi et al., 2005). Another possibility would be to question the accuracy of the temperature determinations. In the studies of (Yokochi et al., 2005; Blard et al., 2006b) temperature was measured on the wall of the crushing tube, several centimeters above the bottom of the tube, which could have resulted in an underestimate of the actual sample temperature (at the bottom of the tube), as a result of a temperature gradient. In contrast, (Moreira and Madureira, 2005) measured the temperature $\left(T=70{ }^{\circ} \mathrm{C}\right)$ at the contact between the sample and the iron slug using a paint especially designed to record maximum temperature. The low level of ${ }^{3} \mathrm{He}_{\mathrm{c}}$ loss $(0.5 \%)$ observed by these authors is thus consistent with our data and the conclusion that, when crushing is performed at low temperature $\left(<100{ }^{\circ} \mathrm{C}\right)$, high level of loss $(>10 \%)$ cannot occur.

\subsection{Does crushing affect ${ }^{3} \mathrm{He}_{\mathrm{c}}$ diffusivity?}

The diffusion experiments performed in this study using two different crushed, irradiated olivines yielded $E_{\mathrm{a}}$ and $D_{0}$ that are not significantly different as those from the previous determinations of (Trull et al., 1991) and (Shuster et al., 2004) for matrix-sited ${ }^{3} \mathrm{He}$ (Table 4 and Fig. 5). However these diffusion coefficients are significantly different from those obtained for magmatic helium (Fig. 6) (Trull and Kurz, 1993). This result is consistent with the previous conclusions of (Trull et al., 1991) and (Trull and Kurz, 1993) stating that, because magmatic helium is most probably trapped within fluid inclusions, this component has a different behavior than matrix-sited helium, leading to very different activation energies and frequency factors (Fig. 6). It should be noted that the $D_{0}$ from (Shuster et al., 2004) has been revised here (Table 4) using a new and more accurate estimate of the equivalent sphere radius of the grain analyzed by (Shuster et al., 2004). This new geometry shape correction from (Meesters and Dunai, 2002) yields an equivalent radius of $470 \mu \mathrm{m}$, leading to a revised value of $-5.1 \pm 0.3 \mathrm{~cm}^{2} \mathrm{~s}^{-1}$ for $\ln D_{0}$ (Table 4).

In the range of temperature considered here (between 100 and $350^{\circ} \mathrm{C}$ ), the diffusion parameters obtained from the crushed olivines are similar to the ones obtained in (Trull et al., 1991) and are about 10 times higher than those determined in (Shuster et al., 2004) (Fig. 5). It has been demonstrated that increasing the density of proton-induced lattice damage can impede the helium diffusivity in some minerals (Shuster and Farley, 2005; Shuster et al., 2006). However, although the olivines used in (Trull et al., 1991) have "natural" concentrations of cosmogenic ${ }^{3} \mathrm{He}$ (several orders of magnitude below the concentrations of the irradiated samples), the diffusivity measured in this sample is similar to the one determined here using irradiated olivines. Consequently, because the concentration of matrix-sited ${ }^{3} \mathrm{He}$ is correlated with the number of radiation tracks, it is improbable that the numerous proton-induced damages have biased the diffusion parameters estimated from the irradiated olivines in this study. Nevertheless, it is not straightforward to propose a mechanism that could have increased the diffusivity of olivines during crushing. Moreover, although the San Carlos and Guadalupe olivines have been crushed under different conditions, both yielded similar diffusivity. Therefore, the influence of crushing-induced fractures within the grains may explain the apparent discrepancy with uncrushed phenocrysts, rather than damage affecting the properties of the mineral lattice. Another possibility is that part (or most) of the discrepancy could be the result of natural variability. Such inter-mineral diffusion variability might result from compositional differences (Farley, 2007).

Finally, it should be noted that, if the diffusivity data previously estimated by (Shuster et al., 2004) or (Trull et al., 1991) had been used to model the release of ${ }^{3} \mathrm{He}_{\mathrm{c}}$ (Fig. 4), the estimated loss would be about one order of magnitude below the observed loss. So, even if crushing has no effect on diffusivity, the newly measured diffusion parameters appear quite relevant and should be considered as an important piece of information for addressing the behavior of ${ }^{3} \mathrm{He}_{\mathrm{c}}$ during crushing.

\subsection{Comments on previous and future studies}

If we accept that volume diffusion is the sole mechanism able to trigger significant $(\gg 1 \%){ }^{3} \mathrm{He}_{\mathrm{c}}$ loss, then the three essential points that should be checked for any crushing apparatus are (i) the actual temperature within the crushed sample, (ii) the duration of crushing and (iii) the grain size distribution of the crushed sample. These considerations are important because they can help assess whether previous determinations of cosmogenic ${ }^{3} \mathrm{He}$ production rates were biased by unexpected crushing loss (Blard et al., 2006b). To exclude this possibility, the most important priority is to determine what temperature is actually reached by the samples within the crushing apparatus. Fig. 7 shows the modeled magnitude of loss at different temperatures, for a 10-min crush. This plot can be used to place constraints on the parameter range ( $T$, time and grain size) that should be used to stay below an acceptable amount of loss during crushing. This calculation used the diffusion equations of (Fechtig and Kalbitzer, 1966) and the diffusion coefficient determined in this study.

Finally, it is important to acknowledge that, in the light of the previous (Scarsi, 2000; Moreira and Madureira, 2005) and the present crushing data, it seems that there 


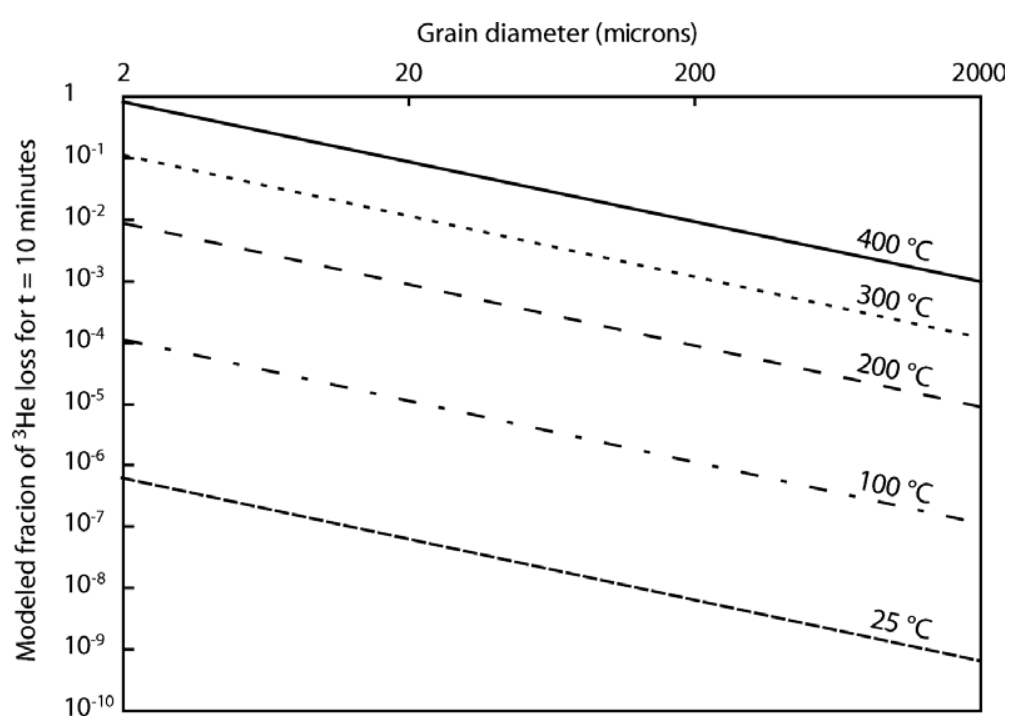

Fig. 7. Modeling of the ${ }^{3} \mathrm{He}_{\mathrm{c}}$ diffusive loss vs. the grain size at variable temperatures during $10 \mathrm{~min}$. This modeling was done assuming grains have a spherical geometry, using the diffusion coefficient established in the present study from the Guadalupe sample (Table 4) and the diffusion equation of (Fechtig and Kalbitzer, 1966).

are some inescapable mechanisms that will yield a loss of about $1 \%$ (and of higher magnitude according to Yokochi et al., 2005 and Blard et al., 2006b), even if the temperature is kept low. The level of loss that can be considered as acceptable for a specific study is highly dependent on the sample characteristics and on the nature of the question being addressed. Indeed, given that the uncertainty associated with the scaling of cosmogenic production rates is at least $10 \%$, then $\sim 1 \%$ of ${ }^{3} \mathrm{He}_{\mathrm{c}}$ loss can be considered as acceptable for studies interested in determining absolute ages measuring cosmogenic ${ }^{3} \mathrm{He}$. On the other hand, as demonstrated by Moreira and Madureira (2005) and Yokochi et al. (2005), if accurate measurement of magmatic ${ }^{3} \mathrm{He} /{ }^{4} \mathrm{He}$ ratio is the main goal of the study, even $0.5 \%$ of ${ }^{3} \mathrm{He}_{\mathrm{c}}$ loss may induce a significant bias on the measured ${ }^{3} \mathrm{He} /{ }^{4} \mathrm{He}$ ratio, this issue being all the more important for samples having a high ${ }^{3} \mathrm{He}_{\mathrm{c}} /{ }^{3} \mathrm{He}_{\text {mag }}$ ratio. Similarly, uncontrolled loss of matrix-hosted radiogenic ${ }^{4} \mathrm{He}$ can also bias the ${ }^{3} \mathrm{He} /{ }^{4} \mathrm{He}$ crushing ratio, in particular for samples that have high $(\mathrm{U}-\mathrm{Th}) /{ }^{3} \mathrm{He}_{\text {mag }}$ ratio and old closure ages.

\section{CONCLUSIONS}

Crushing experiments performed on a suite of olivines and pyroxenes with various amounts of matrix-sited ${ }^{3} \mathrm{He}$ demonstrated that significant helium extraction $(>1 \%)$ was manifest only under hot conditions $\left(T \geqslant 300{ }^{\circ} \mathrm{C}\right)$. Moreover, the ${ }^{3} \mathrm{He}_{\mathrm{c}}$ measured within each size fraction showed that the ${ }^{3} \mathrm{He}_{\mathrm{c}}$ loss $(>20 \%)$ only affected the finest fraction $(<10 \mu \mathrm{m})$. These observations imply that the previously proposed mechanism involving spallation tracks is invalid (Yokochi et al., 2005), given the loss predicted by this model should be $>10 \%$ for the $<10 \mu \mathrm{m}$ fraction, even at low temperature. Consequently, temperature appears to be an essential parameter that should be carefully controlled and considered in any studies involving vacuum crushing, such as cosmogenic ${ }^{3} \mathrm{He}$ determinations. However, while volume diffusion is the predominant mechanism responsible for helium loss, other extraction mechanisms are probably responsible for an additional ${ }^{3} \mathrm{He}_{\mathrm{c}}$ loss, whose magnitude is at least $\sim 1 \%$, even under cold conditions. Moreover, for the specific case of the CRPG laboratory, a significant part of the crushing-loss magnitude observed in this lab (Yokochi et al., 2005; Blard et al., 2006b) is probably not due to volume diffusion. This suggests that the mechanisms responsible of the crushing loss may vary and be specific to the particular crushing apparatus in each laboratory. Because these mechanisms are still poorly understood, this apparently unavoidable loss should be carefully considered and tested.

Finally, the accuracy of cosmogenic ${ }^{3} \mathrm{He}$ measurement may also benefit from alternative strategies that avoid the vacuum crushing step, such as those based on the building of cosmogenic isochrons (Cerling and Craig, 1994; Blard and Pik, 2008).

\section{ACKNOWLEDGMENTS}

This article benefited from the constructive comments by Mark Kurz, David Shuster, Rainer Wieler and an anonymous reviewer. The authors are grateful to Janet Sisterson for proton irradiation of the samples at Harvard Cyclotron Laboratory. The authors sincerely thank Lindsey Hedges and Hak-No Lee for their valuable technical assistance in the Caltech noble gas laboratory. This work is part of the OK Earl Post-Doctoral Fellowship of P.-H. Blard.

\section{REFERENCES}

Andrews J. N. (1985) The isotopic composition of radiogenic helium and its use to study groundwater movement in confined aquifers. Chem. Geol. 49, 339-351.

Andrews J. N. and Kay R. L. F. (1982) Natural production of tritium in permeable rocks. Nature 298, 361-363.

Batiza R. (1977) Petrology and chemistry of Guadalupe Island: an alkalic seamount on a fossil ridge crest. Geology 5, 760-764. 
Blard P.-H., Bourlès D., Lavé J. and Pik R. (2006a) Applications of ancient cosmic-ray exposures: theory, techniques and limitations. Quatern. Geochronol. 1, 59-73.

Blard P.-H., Pik R., Lavé J., Bourlès D., Burnard P. G., Yokochi R., Marty B. and Trusdell F. (2006b) Cosmogenic ${ }^{3} \mathrm{He}$ production rates revisited from evidences of grain size dependent release of matrix sited helium. Earth Planet. Sci. Lett. 247, 222-234.

Blard P.-H. and Pik R. (2008) An alternative isochron method for measuring cosmogenic ${ }^{3} \mathrm{He}$ in lava flows. Chem. Geol. 251, 20-32.

Blard P.-H., Lavé J., Pik R., Wagnon P. and Bourlès D. (2007) Persistence of full glacial conditions in the central Pacific until 15,000 years ago. Nature 449, 591-594.

Blard P.-H., Lave J., Farley K. A., Tripati A., Eiler J. M., Sylvestre F. and Fornari M. (2008) Late glacial paleoclimate of the central Altiplano constrained by cosmogenic ${ }^{3} \mathrm{He}$ dating and 'clumped-isotope' paleothermometry. Goldschimdt Conference, July 13-18, Vancouver. Geochim. Cosmochim. Acta., 72 , A41-A126.

Burnard P. G. and Farley K. A. (2000) Calibration of pressure dependent sensitivity and discrimination in Nier-type noble gas ion sources. Geochem. Geophys. Geosyst., doi:10.1029/ $2000 \mathrm{GC} 000038$.

Cerling T. E. and Craig H. (1994) Geomorphology and in-situ cosmogenic isotopes. Ann. Rev. Earth Planet. Sci. 22, 273-317.

Eiler J. M., Farley K. A., Valley J. W., Hofmann A. W. and Stolper E. M. (1996) Oxygen isotope constraints on the sources of Hawaiian volcanism. Earth Planet. Sci. Lett. 144, 453-467.

Farley K. A. (2007) He diffusion systematics in minerals: evidence from synthetic monazite and zircon structure phosphates. Geochim. Cosmochim. Acta 71, 4015-4024.

Farley K. A., Reiners P. W. and Nenow V. (1999) An apparatus for high precision helium diffusion measurements from minerals. Anal. Chem. 71, 2059-2061.

Farley K. A., Libarkin J., Mukhopadhyay S. and Amidon W. (2006) Cosmogenic and nucleogenic ${ }^{3} \mathrm{He}$ in apatite, titanite, and zircon. Earth Planet. Sci. Lett. 248, 451-461.

Fechtig H. and Kalbitzer S. (1966) The diffusion of argon in potassium bearing solids. In Potassium-Argon Dating (eds. O. A. Schaeffer and J. Zahringer). Springer, Heidelberg.

Finkel R. C., Kohl C. P., Marti K., Martinek B. and Rancitelli L. (1978) Cosmic-ray record in San-Juan Capistrano meteorite. Geochim. Cosmochim. Acta 42, 241-250.

Frey F. A. and Prinz M. (1976) Ultramafic inclusions from San Carlos, Arizona: petrological and geochemical data bearing on their petrogenesis. Earth Planet. Sci. Lett. 38, 559-567.

Hilton D. R., Gronvold K., Macpherson C. G. and Castillo P. R. (1999) Extreme ${ }^{3} \mathrm{He} /{ }^{4} \mathrm{He}$ ratios in northwest Iceland: constraining the common component in mantle plumes. Earth Planet. Sci. Lett. 173, 53-60.

Kurz M. D. (1986a) Cosmogenic helium in a terrestrial igneous rock. Nature 320, 435-439.

Kurz M. D. (1986b) In situ production of terrestrial cosmogenic helium and some applications to geochronology. Geochim. Cosmochim. Acta 50, 2855-2862.

Kurz M. D., Jenkins W. J. and Hart S. R. (1982) Helium isotopic systematics of Oceanic Islands and mantle heterogeneity. Nature 297, 43-47.

Kurz M. D., Jenkins W. J., Hart S. R. and Clague D. (1983) Helium isotopic variations in volcanic-rocks from Loihi Seamount and the Island of Hawaii. Earth Planet. Sci. Lett. 66, 388-406.
Kurz M. D., Colodner D., Trull T. W., Moore R. B. and Obrien K. (1990) Cosmic-ray exposure dating with in situ produced cosmogenic ${ }^{3} \mathrm{He}$ - results from young Hawaiian lava flows. Earth Planet. Sci. Lett. 97, 177-189.

Lippolt H. J. and Weigel E. (1988) ${ }^{4} \mathrm{He}$ diffusion in ${ }^{40} \mathrm{Ar}$-retentive minerals. Geochim. Cosmochim. Acta 52, 1449-1458.

Meesters A. and Dunai T. J. (2002) Solving the productiondiffusion equation for finite diffusion domains of various shapes. Part 1: Implications for low-temperature (U-Th)/He thermochronology. Chem. Geol. 186, 333-344.

Moreira M. and Madureira P. (2005) Cosmogenic helium and neon in $11 \mathrm{Myr}$ old ultramafic xenoliths: consequences for mantle signatures in old samples. Geochem. Geophys. Geosyst., doi:10.1029/2005GC000939.

Patterson D. B. and Farley K. A. (1998) Extraterrestrial ${ }^{3} \mathrm{He}$ in seafloor sediments: evidence for correlated $100 \mathrm{kyr}$ periodicity in the accretion rate of interplanetary dust, orbital parameters, and Quaternary climate. Geochim. Cosmochim. Acta 62, 36693682 .

Scarsi P. (2000) Fractional extraction of helium by crushing of olivine and clinopyroxene phenocrysts: effects on the ${ }^{3} \mathrm{He} /{ }^{4} \mathrm{He}$ measured ratio. Geochim. Cosmochim. Acta 64, 3751-3762.

Shuster D. L. and Farley K. A. (2005) Diffusion kinetics of protoninduced ${ }^{21} \mathrm{Ne},{ }^{3} \mathrm{He}$, and ${ }^{4} \mathrm{He}$ in quartz. Geochim. Cosmochim. Acta 69, 2349-2359.

Shuster D. L., Farley K. A., Sisterson J. M. and Burnett D. S. (2004) Quantifying the diffusion kinetics and spatial distributions of radiogenic ${ }^{4} \mathrm{He}$ in minerals containing proton-induced ${ }^{3}$ He. Earth Planet. Sci. Lett. 217, 19-32.

Shuster D. L., Flowers R. M. and Farley K. A. (2006) The influence of natural radiation damage on helium diffusion kinetics in apatite. Earth Planet. Sci. Lett. 249, 148-161.

Stuart F. M., Lass-Evans S., Fitton J. G. and Ellam R. M. (2003) High ${ }^{3} \mathrm{He} /{ }^{4} \mathrm{He}$ ratios in picritic basalts from Baffin Island and the role of a mixed reservoir in mantle plumes. Nature 424, 5759.

Trull T. W. and Kurz M. D. (1993) Experimental measurements of ${ }^{3} \mathrm{He}$ and ${ }^{4} \mathrm{He}$ mobility in olivine and clinopyroxene at magmatic temperatures. Geochim. Cosmochim. Acta 57, 1313-1324.

Trull T. W., Kurz M. D. and Jenkins W. J. (1991) Diffusion of cosmogenic ${ }^{3} \mathrm{He}$ in olivine and quartz-implications for surface exposure dating. Earth Planet. Sci. Lett. 103, 241-256.

Villeneuve M. E., Pérez de Arce C., Uribe-Zeballos H., Zappettini E., Hickson C. J. and Stasiuk M. V. (2002) Geochronological compilation for the border region between Argentina, Bolivia, Chile and Peru $\left(14^{\circ} \mathrm{S}-28^{\circ} \mathrm{S}\right)$. In Proyecto Multinacional Andinol Multinational Andean Project GeoData CD-ROM (eds. A. J. Makepeace, M. V. Stasiuk, O. R. Krauth, C. J. Hickson, R. B. Cocking and D. M. Ellerbeck). Publicación Geológica Multinacional/Multinational Geological Publication, Hull, Canada.

Wolfe E. W., Wise W. S. and Dalrymple G. B. (1997) The Geology and Petrology of Mauna Kea Volcano, Hawaii-A Study of Postshield Volcanism. U.S. Geological Survey professional paper 1557.

Yokochi R., Marty B., Pik R. and Burnard P. (2005) High ${ }^{3} \mathrm{He} /{ }^{4} \mathrm{He}$ ratios in peridotite xenoliths from SW Japan revisited: evidence for cosmogenic ${ }^{3} \mathrm{He}$ released by vacuum crushing. Geochem. Geophys. Geosyst. 6. doi:10.1029/2004GC000836.

Associate editor: Rainer Wieler 